\title{
Documentos pictográficos de la Mixteca Baja de Oaxaca: el Lienzo de San Vicente el Palmar, el Mapa núm. 36 y el Lienzo Mixteca III*
}

\author{
Sebastián van Doesburg
}

De los diez documentos pictográficos provenientes de la Mixteca Baja, cuatro destacan por su composición cartográfica similar: el Lienzo de San Vicente el Palmar, el Mapa núm. 36, el Lienzo Mixteco III y el Mapa de Xochitepec. El principal problema en la interpretación de estos documentos es la falta de una clara referencia a sus lugares de origen. En esta contribución, el autor trata de identificar el origen de los primeros tres. El Lienzo de San Vicente el Palmar parece provenir del señorío Ihualtepec, los dos restantes del señorío vecino de Atoyac. Un tema recurrente en estos documentos lo forman los manantiales de agua salada que fueron explotados desde la época prehispánica para la producción de la sal.

PALABRAS CLAVE: documentos pictográficos, Mixteca Baja, siglo XVI, señoríos, producción de sal

\section{Pictographic Documents of the Mixteca Baja in Oaxaca: Lienzo de San Vicente el} Palmar, Mapa núm. 36 and Lienzo Mixteca III

Among the ten most important pictographic documents from the Mixteca Baja, four stand out because of their similar cartographic composition: the Lienzo de San Vicente del Palmar, the Mapa núm. 36, the Lienzo Mixteco III, and the Mapa de Xochitepec. The interpretation of these documents faces one main difficulty: the absence of any clear references to their places of origin. This paper attempts to identify the origin of the first three documents. The Lienzo de San Vicente el Palmar appears to come from the kingdom of lhualtepec, and the other two from the neighboring kingdom of Atoyac. The salty water springs used for salt production since the prehispanic period constitutes a recurrent topic in these documents.

KEY WORDS: Pictographic Documents, Mixteca Baja, Sixteenth Century, Mixtec Kingdoms, Salt Production

SEBASTIÁN VAN DOESBURG: Biblioteca Francisco de Burgoa, Universidad Autónoma Benito Juárez de Oaxaca, Oaxaca, México. basborb@hotmail.com

* Agradezco el entusiasmo y la ayuda de Rubén Luengas, Patricia García y Luis Octavio Castro de Tezuatlán durante los recorridos realizados en la primera mitad de 2006, y la información que amablemente me proporcionaron las señoras Irma Urraga Rivera de San Ildefonso Salinas y Gloria Reyes y Andrea Sánchez de San Bartolo Salinas. Agradezco a Alexander Brust, del Departamento de América del Museo de las Culturas de Basilea, su ayuda para localizar todo lo referente al Lienzo Mixteco III. 


\section{INTRODUCCIÓN}

$\mathrm{D}$ esde que Alfonso Caso logró demostrar que la Mixteca Alta (véase mapa 1, p. XX) fue el lugar de origen de todo un grupo de documentos pictográficos de singular belleza y riqueza que versan sobre la historia de los señoríos indígenas de origen prehispánico, esta región ha sido objeto de múltiples estudios arqueológicos, codicológicos, antropológicos y etnohistóricos ${ }^{1}$. En los más de sesenta años que han pasado desde los descubrimientos de Caso, estos estudios han revelado la larga trayectoria histórica de las culturas de la Mixteca Alta. También demostraron que los documentos pictográficos y, sobre todo, los códices, en cuanto a su contenido, se remiten a la época Posclásica y sus secuelas en el primer siglo del dominio español (950-1600). Caso demostró que estos documentos relatan historias sagradas de la creación, largas historias dinásticas o antiguas biografías. Su trabajo fue continuado por Mary Elizabeth Smith, quien se dedicó sobre todo al estudio de los lienzos pictográficos que registran —según sabemos hoy en día- aspectos particulares de los señoríos del siglo XVI, como la creación o fijación de los linderos, la negociación de matrimonios, la explicación de terrenos en conflicto o algún otro acuerdo entre dos casas gobernantes ${ }^{2}$. En este sentido, el 'desciframiento' de la escritura, basado en un reducido grupo de documentos en los primeros años de Caso, fue seguido por la búsqueda de otros documentos pictóricos y un mayor énfasis en el método de investigación ${ }^{3}$. El corpus de documentos pictográficos conocido

\footnotetext{
${ }^{1}$ Para mencionar sólo algunos estudios: Caso, 1949, 1977-1979; Paddock, 1953; Dahlgren de Jordan, 1954; Smith, 1963, 1998; Spores, 1967, 1984; Parmenter, 1966, 1997; Troike, 1974; Rabin, 1974, 2003; Gaxiola, 1976; Furst, 1978; Romero Frizzi, 1975, 1990; Jansen, 1979; Jansen y Pérez Jiménez, 2005; Lind, 1979; Flannery y Marcus, 1983; Byland, 1980; Pohl, 1984.

${ }^{2}$ No comparto la idea, propuesta originalmente por Mary Elizabeth Smith (1973: 169) y hoy muy difundida, de que los lienzos fueron elaborados para ser usados en las cortes españolas. Es más probable que este tipo de documento - sobre todo los más complejos— sirvió para ser discutido y comentado dentro de las comunidades indígenas.

${ }^{3}$ Un trabajo fundamental y sistemático es Smith, 1973, en el que queda demostrado el gran potencial del estudio de la documentación colonial alfabética en la interpretación de los lienzos. Jansen, p.e. 1988, 2000; Boone y Mignolo, 1994; Boone, 2000, y Doesburg, 2001a, han escrito
}

hoy constituye una fuente extraordinaria para indagar sobre el desarrollo de los múltiples señoríos que existieron en la Mixteca durante la época posclásica y colonial temprana y sus aspectos sociales, religiosos, ideológicopolíticos, etc. A pesar de la fragmentación política característica de esta región durante la época Posclásica, las historias comparten episodios que abarcaron toda la Mixteca Alta y que funcionaron como elementos políticamente integradores, como las famosas historias del gobernante 8 -Venado y de la princesa 6-Mono.

La Mixteca Alta colinda al noroeste con la región conocida como la Mixteca Baja. Desde hace algunas décadas se sabe que la Mixteca Baja tuvo un desarrollo cultural similar, pero no idéntico, al de la Mixteca Alta. Así, durante la época Clásica (250-800) se distingue un estilo propio llamado ñuiñe en los materiales arqueológicos de esta región ${ }^{4}$. No obstante, para la época Posclásica no contamos aún con una definición de los rasgos culturalesartísticos distintivos — si los hubo-y la expresión artística de la Mixteca Baja se incluye de manera generalizada dentro del estilo característico posclásico que se ha llamado 'Mixteca-Puebla's . Una de las expresiones más exquisitas de este estilo la conforman precisamente las pinturas polícromas de los documentos pictográficos. No debe sorprender entonces que la Mixteca Baja sea el lugar de origen de varios de estos documentos. A pesar de este hecho, la arqueología, la etnohistoria y los estudios codicológicos de la Mixteca Baja están aún en su infancia.

Los primeros estudios de los documentos pictográficos de la Mixteca Baja fueron emprendidos por Alfonso Caso, Viola König y Mary Elizabeth Smith 6 . Smith publicó un resumen más o menos sistemático del estado de

sobre el método de la 'lectura' de la pictografía. Loo, 1987, se ha dedicado al método del estudio de los documentos mánticos.

4 Para mencionar algunos estudios: Paddock, 1965, 1966, 1968, 1970a, 1970b; Moser, 1972, 1977; Winter et al., 1976; Winter, 1989, 1996; Rodríguez Cano, 1995,y más recientemente, Rivera Guzmán, 1999, y Urcid, 2004

${ }^{5}$ Nicholson, 1960; Nicholson y Quiñones Keber, 1984. Existen, sin embargo, ciertas particularidades en la Mixteca Baja (p.e. el patrón de descendencia) que marcan diferencias con la Mixteca Alta.

${ }^{6}$ Caso, 1958, sobre el Mapa de Xochitepec; König, 1979, sobre el Códice Egerton 2895; Smith, 1973, sobre el Mapa núm. 36; Smith, 1979, sobre el Códice Becker II; Smith y Parmenter, 1991, sobre el Códice Tulane. 
MAYO-AGOSTO 2008

Desacatos

SABERES Y RAZONES

- Tepexi

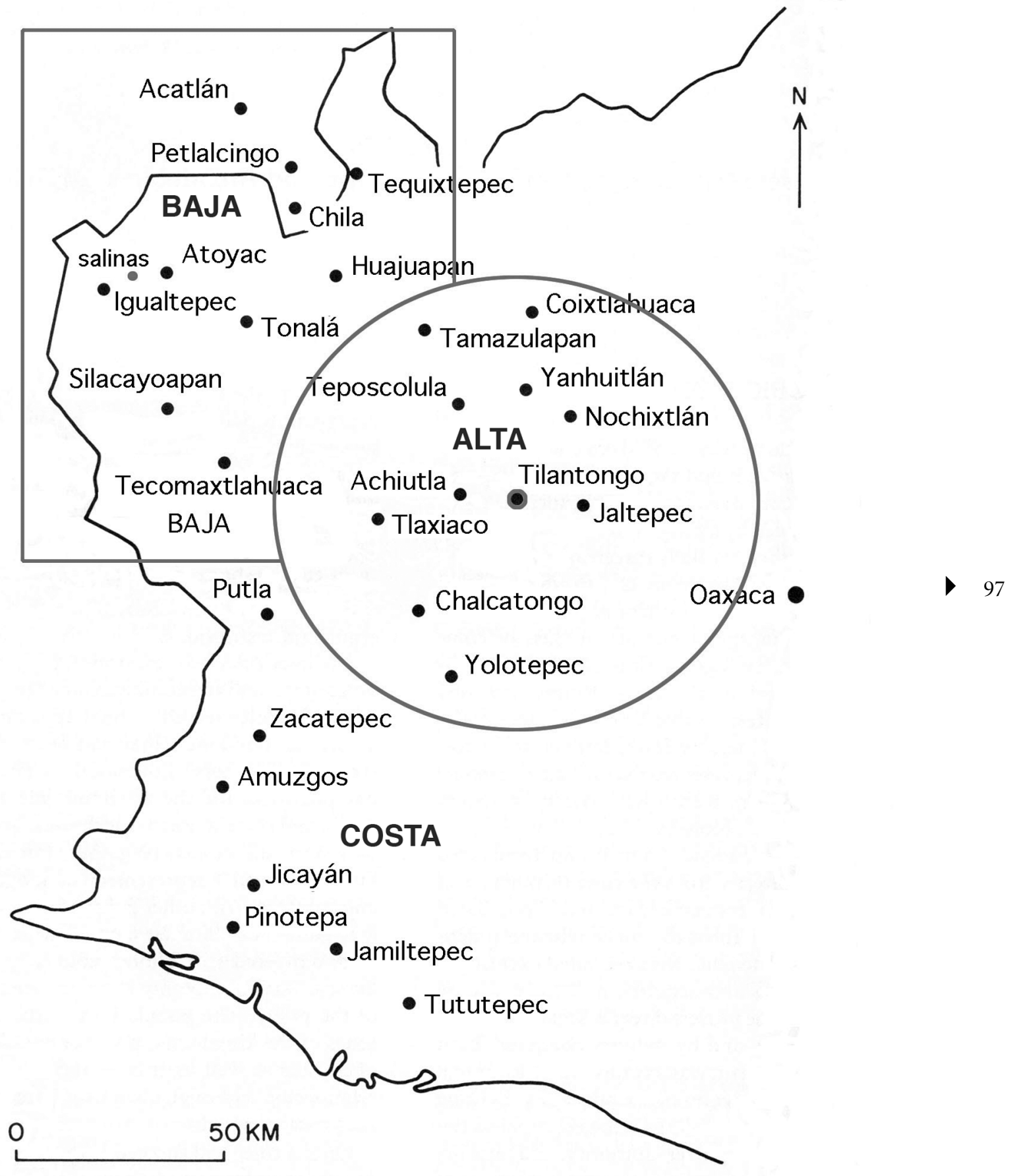

Mapa 1. La Mixteca Alta y Baja 
las cosas en 1991 y mencionó nueve manuscritos provenientes de la zona. A éstos habría que añadir la recién redescubierta Genealogía de Igualtepec ${ }^{7}$. Dentro de este grupo, el Mapa núm. 36 y su variante, el Lienzo Mixteco III de Saussure (conservados respectivamente en México y Ginebra), el Lienzo de San Vicente el Palmar (en el pueblo que lleva este nombre) y el Mapa de Xochitepec (en Copenhague) conforman un grupo de cuatro documentos que se caracteriza por su similar composición cartográfica y su similitud estilística. Este grupo es el objeto de un estudio que actualmente llevo a cabo y que tiene como meta entender mejor la constitución interna y las relaciones externas de los señoríos de la Mixteca Baja.

Un problema en el estudio de este grupo es la falta de un origen preciso para los documentos. Esta situación limita en gran medida la utilidad de los documentos como fuentes históricas ${ }^{8}$. El problema de la procedencia fue abordado en varias ocasiones, pero sin mucho éxito. Caso publicó un breve estudio del Mapa de Xochitepec en 1958, en el que sugirió que este mapa pudo venir de San Juan Xuchitepec en el distrito de Huajuapan (Caso, 1958). der confirmar su sugerencia ${ }^{9}$. Smith sugirió en 1973 que el Mapa núm. 36 podría ser de Huajuapan por una glosa que, aparentemente, representa el nombre mixteco de Huajuapan, escrita en un edificio dibujado en el documento, pero hasta ahora no se ha dado seguimiento a esta sugerencia. Además, ella misma reconoció que su propuesta padeció de varios problemas. Finalmente, Smith

\footnotetext{
${ }^{7}$ El documento está mencionado con el núm. 156 en Handbook of Middle American Indians, vol. 14, 1975, pero los recopiladores de este censo lo conocían sólo a través de una fotografía en la Colección de Gates en la Universidad Brigham Young, Provo. El original fue localizado por coincidencia en la Biblioteca Lafragua, donde lo identifiqué como el número 156 en mayo de 2006. Agradezco al director de la Biblioteca Lafragua, Manuel de Santiago Hernández, el permiso para estudiar éste y otros documentos.

${ }^{8}$ En el caso del Lienzo de San Vicente el Palmar existe otro elemento de vigencia actual, ya que la población dio a conocer el documento hace poco con la esperanza de que éste podría ser de alguna utilidad en su añejo conflicto con una comunidad vecina. Por lo mismo, la identificación de la geografía representada era de importancia para los actuales habitantes.

${ }^{9}$ En el centro del documento hay un cerro con una flor y la glosa $x u$ chitepeque. Smith (1998: 159) se mostró escéptica en cuanto a esta identificación.
}

sugirió que el Lienzo de San Vicente, por su actual ubicación, podría representar a San Vicente "estableciendo su relación con sus vecinos más grandes e importantes, Huajuapan en la parte superior del mapa y posiblemente Tonalá abajo" ${ }^{10}$. En esta ocasión abordaré de nuevo el asunto del lugar de origen de estos documentos.

Otro de los objetivos del presente texto — ciertamente relacionado con el objetivo descrito más arriba- es insistir en la productividad del método de la contextualización de los documentos pictográficos. Métodos actualmente en boga, como el método Galarza ${ }^{11}$, que equivocadamente $-\mathrm{y}$ sobre bases más bien ideológicas que científicas - presuponen que la pictografía mesoamericana del Posclásico es una suerte de escritura logográfica, han desviado la atención de los investigadores hacia la 'disección’ de las imágenes — con la esperanza de encontrar allí algún mensaje 'legible’-, sin reconocer la aportación que disciplinas clásicas como la filología y la iconología puedan hacer a la interpretación del 'mensaje' de los documentos (que incluye el porqué o para qué ocasión fueron pintados), siempre desde un acercamiento contextualizador -en su tiempo, en su contorno cultural y sociopolítico- ${ }^{12}$. Este último punto de partida implica más bien una visión hacia afuera, que incorpore los elementos - principalmente otras fuentes pictóricas o textos alfabéticos- que puedan ayudar a reconstruir y entender el contexto en que fue elaborado cada documento, apuntando así a una lectura 'profunda' del mismo. Pare-

\footnotetext{
${ }^{10}$ Smith, en Smith y Parmenter, 1991: 95. Véase Hermann Lejarazu, 1998, para un resumen de la interpretación de Smith.

${ }^{11}$ Para el método de Joaquín Galarza, véase, por ejemplo, Galarza, 1979, y el reciente número 22 de Desacatos.

${ }^{12}$ A lo largo de su carrera, Joaquín Galarza afirmó que la resistencia a su método de análisis tenía que ver con prejuicios culturales académicos (p.e. la supuesta resistencia a aceptar a la pictografía mesoamericana como 'escritura' en la tradicional y restringida definición del término). Fue, sin embargo, él mismo quien trató de colocar - forzosamente - esta pictografía dentro de tal definición, en lugar de combatir el reducido marco teórico de la definición de 'escritura'. Esta discusión, por cierto artificial e ideológica, quedó rebasada desde hace varias décadas por los estudios de Sampson, 1985, y otros. El método de Galarza desafortunadamente descarta — de nuevo sobre bases más bien ideológicas - la información de las fuentes alfabéticas y busca generar una lectura exclusivamente desde la pictografía misma. En lugar de enriquecer el método, esto más bien ha significado una limitación al estudio de la documentación mesoamericana.
} 
ce innecesario - excepto por razones de protagonismo excesivo- apartarse del camino productivo establecido por Alfonso Caso, Mary Elizabeth Smith, Maarten Jansen y otros, quienes ya establecieron con éxito - durante el último medio siglo_ — las bases de la interpretación de la pictografía oaxaqueña como un sistema semasiográfico, distinto de los sistemas logocéntricos o fonéticos ${ }^{13}$.

\section{LOS LIENZOS DE LA MIXTECA BAJA}

El Lienzo de San Vicente el Palmar fue visto por Mary Elizabeth Smith, la pareja Welte y Ross Parmenter durante un viaje al pueblo en $1982^{14}$. Smith localizó además una copia del documento en el archivo de la Secretaría de la Reforma Agraria en Oaxaca. Impulsada por su interés en esta copia, Laura Rodríguez Cano comenzó un estudio descriptivo del lienzo y de los otros documentos del grupo en $2000^{15}$. Como consecuencia de sus gestiones, el lienzo original (fig. 1) está actualmente en restauración en el taller del Centro Cultural Santo Domingo en Oaxaca ${ }^{16}$.

${ }^{13}$ Véanse Sampson, 1985, y DeFrancis, 1989, para la discusión en cuanto a la clasificación de los sistemas de escritura, y Boone y Mignolo, 1994, para una aplicación a la pictografía mesoamericana. La actual discusión teórica ha dejado atrás la teleología anticuada de Gelb, que tuvo secuelas en las teorías de Galarza, y propone una reconciliación entre los que buscan una 'escritura' en el sentido tradicional y los que señalan las limitaciones de los sistemas 'pictográficos' (cf. Herrera y Ruiz, 2000). En la semasiografía, los signos adquieren significado por medio de su interrelación y de las estructuras convencionales que conforman y a las que pertenecen. La interpretación o 'lectura' se logra, entonces, por medio del análisis de la 'codificación iconográfica', la cual genera el significado. Sin embargo, la codificación estaba directamente relacionada con la tradición oral que acompañaba todo documento en la tradición mesoamericana. Aunque la inevitable pérdida de las particularidades de esta tradición puede parecer un obstáculo en la interpretación, los estudios de los últimos cincuenta años han demostrado que las fuentes alfabéticas de la época y el trabajo de campo en las comunidades actuales permiten la reconstrucción de sus distintos géneros y temáticas (o 'unidades temáticas' en el método iconológico) en términos generales.

${ }^{14}$ Posiblemente en esa ocasión se tomaron fotografías a color, una de las cuales está hoy en día en la colección fotográfica de la Fundación Bustamante en Oaxaca.

15 Véase su informe en el sitio <www.famsi.org >

${ }^{16}$ Quiero agradecer a Laura Rodríguez Cano la posibilidad de estudiar el lienzo. Sin su trabajo con la comunidad no hubiera sido posible realizar este estudio. De igual manera, quiero agradecer a Naú Victorino Enríquez, ingeniero proveniente de San Vicente el Palmar, su confianza y su apoyo entusiasta al estudio del documento.

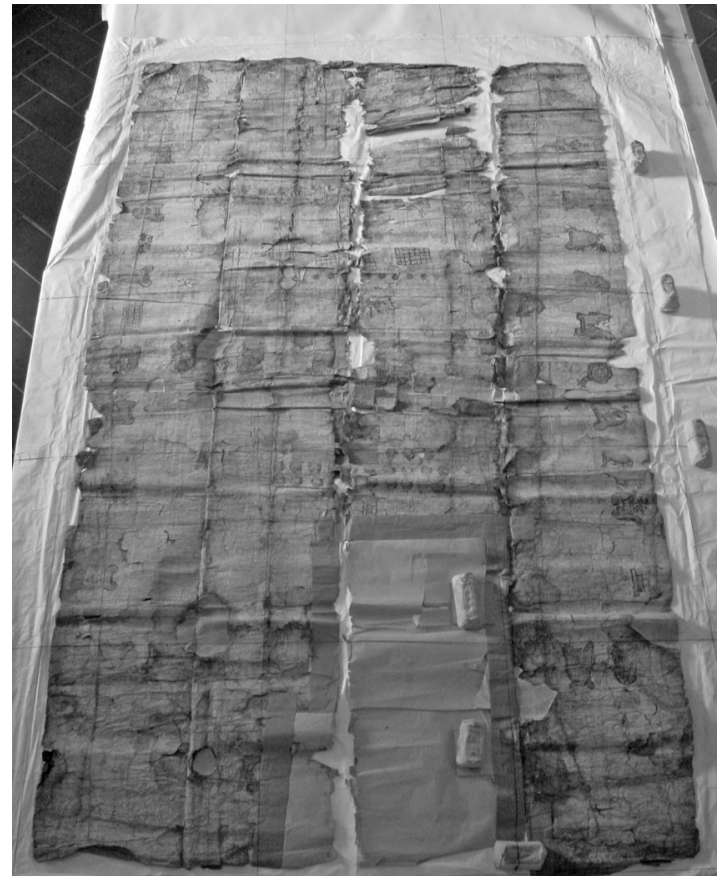

Figura 1. El Lienzo de San Vicente el Palmar al comenzar su restauración.

El documento, pintado en papel de amate ${ }^{17}$, está muy dañado, lo que dificulta considerablemente su interpretación. No obstante, su composición general está clara y la describimos a continuación. En la parte inferior se distingue un rectángulo formado por una serie de topogramas, lo cual es una típica representación del territorio de un señorío o de una comunidad y de sus límites (esquema 1, p. 100) ${ }^{18}$. Dentro de este territorio, la comunidad princi-

${ }^{17} \mathrm{El}$ tamaño del documento, después de su restauración, es de $2.14 \mathrm{x}$ $1.21 \mathrm{~cm}$. El mapa consiste en dos capas de papel de amate, pero es probable que originalmente hubiesen sido cuatro o más capas para darle firmeza. La capa superior, sobre la cual se pintó, se compone de aproximadamente 22 piezas de papel amate armadas en un mosaico. La base de preparación para recibir la pintura está hecha con yeso, posiblemente mezclado con almidón de maíz. El rojo es tinta de cochinilla, el azul y verde están fabricados con base en índigo, y el negro en carbón; las glosas están escritas con una tinta ferrogálica (información de la licenciada María del Refugio Gutiérrez, encargada de la restauración del documento).

${ }^{18}$ Estamos aquí frente a una primera interpretación o 'lectura' derivada del reconocimiento de una estructura iconográfica compuesta por signos interrelacionados. El significado de los topogramas no se deriva 
pal está representada por una iglesia, frente a la cual se observa un grupo de cabezas humanas (fig. 2). El título $y y a$, 'señor gobernante', en las glosas que acompañan a las cabezas indica que se trata probablemente de una lista de gobernantes del lugar, o sea, de una genealogía de la familia real ${ }^{19}$. Los topogramas del lado superior del rectángulo forman, a su vez, el lado inferior de un segundo rectángulo arriba del primero. También en este rectángulo se distingue una iglesia y abajo otro grupo de cabezas humanas, que forman también una genealogía de yya, dirigidas hacia un gobernante sentado en un trono a la derecha, no visible en la fotografía (fig. 3). Más arriba, fuera del segundo rectángulo, se distingue un gobernante sentado en un trono que lleva la glosa Francisco Gómez (fig. 4, p. 102). Desafortunadamente, sus alrededores están muy destruidos: frente a él hay un gran hoyo en el documento; detrás suyo hay otro personaje identificado por una glosa, desafortunadamente demasiado dañada para ser interpretada. Por los restos visibles (las rodillas de una persona sentada, una mano puesta sobre la rodilla), esta persona parece ser una mujer. una pequeña región aparte (fig. 5, p. 103). Dentro de esta zona se separaron otras áreas aún más chicas, en las cuales están pintados unos rectángulos subdivididos en pequeños cuadritos que representan, quizás, algún tipo de terreno. Dos de las partes separadas (cada una con dos rectángulos subdivididos) están relacionadas con sendas

de su composición interna (ya que no hay manera de distinguir con criterios formales un topograma que representa el nombre de una comunidad de uno que representa el nombre de un lindero), sino de su lugar en una composición convencional. Tal composición ha sido llamada la 'unidad temática,' asociación significativa,' 'conjunto similar' o 'tema básico', términos distintos para un instrumento metódico similar (véase Loo, 1987). La identificación de las unidades temáticas está íntimamente relacionada con el problema del 'género' del documento, el cual, en este caso, sería el de la cartografía indígena (definición territorial, acceso a recursos naturales, etc.).

${ }^{19}$ Aunque en la Mixteca Alta las listas de gobernantes en este tipo de documentos están, por lo general, organizadas de manera vertical, con las generaciones más antiguas abajo (cf. Lienzo de Nativitas, Lienzo de Ihuitlán, etc.), el Mapa de Xochitepec contiene una representación horizontal de señores (los últimos cuatro a la derecha llevan nombres cristianos), que explica la representación más 'abreviada' de filas horizontales de cabezas en el Lienzo de San Vicente el Palmar. Quizás tenemos aquí una particularidad de la pictografía de la Mixteca Baja.

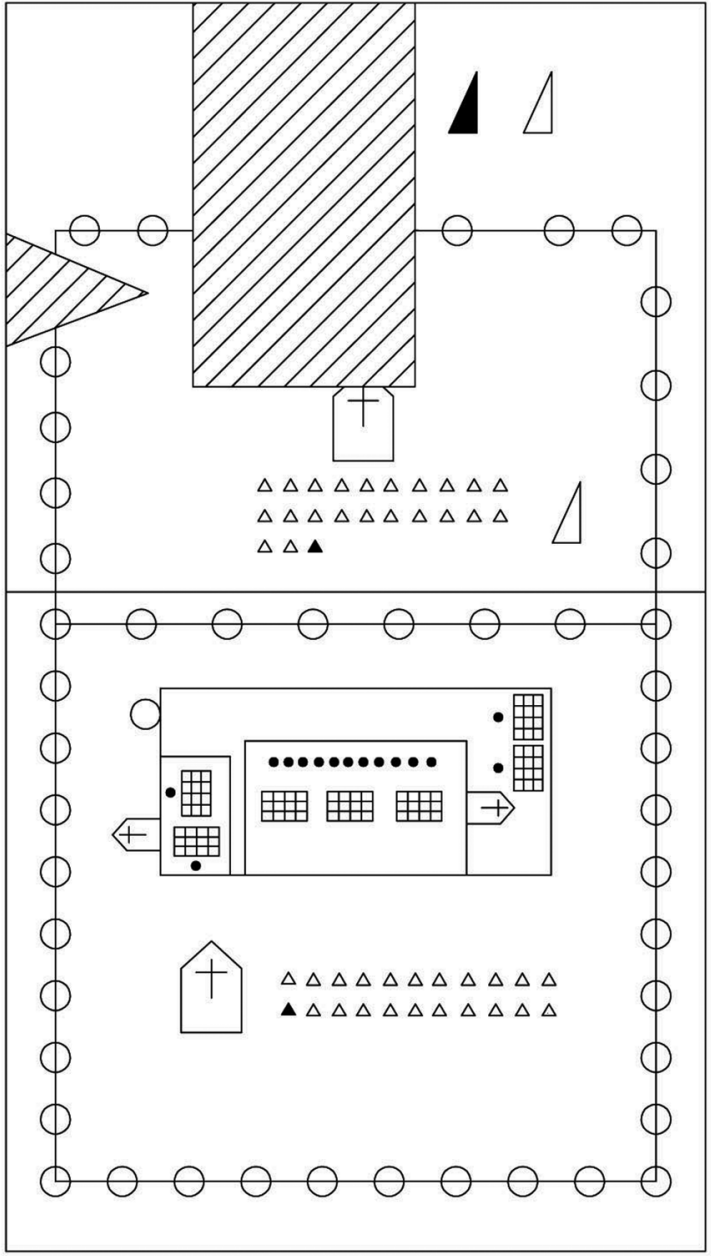

Esquema 1. Esquema general que muestra la composición del Lienzo de San Vicente el Palmar. Los círculos representan topogramas; los triángulos, personas.

capillas y representan pequeñas poblaciones. Una tercera parte contiene tres rectángulos, pero ninguna capilla. Discutiré posteriormente el significado de estos rectángulos y de los puntos negros que parecen estar relacionados con ellos.

Estas áreas separadas están limitadas, sobre todo en sus esquinas, por plantas y árboles —en lugar de topogramas-, lo que sugiere que se trata de unidades territoriales muy locales: en documentos coloniales de los pueblos indígenas de Oaxaca - y aún hoy en día- es común referirse a ciertas plantas, arbustos o árboles sobresalien- 


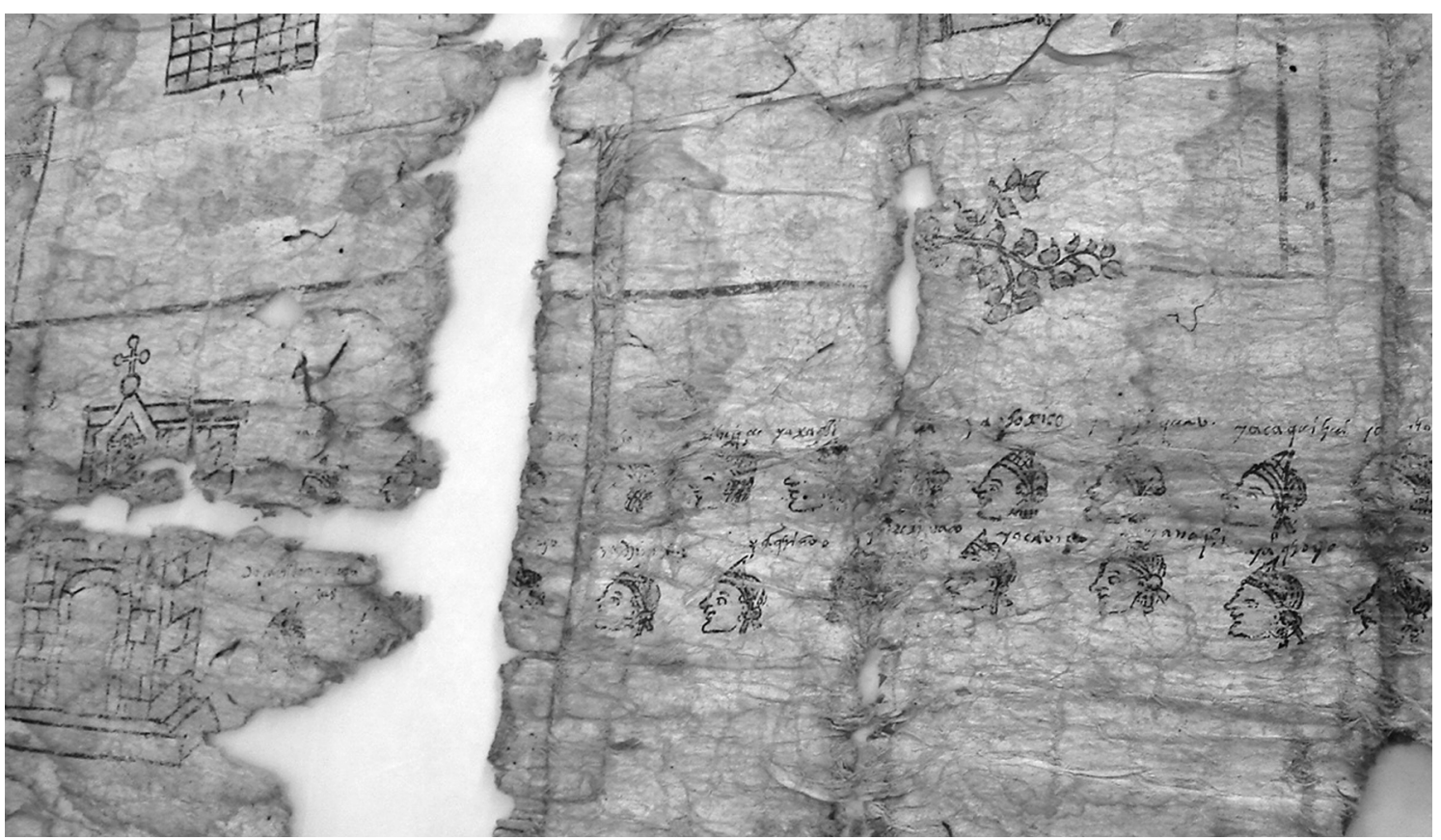

Figura 2. La lista de yya en el señorío inferior del Lienzo de San Vicente el Palmar.

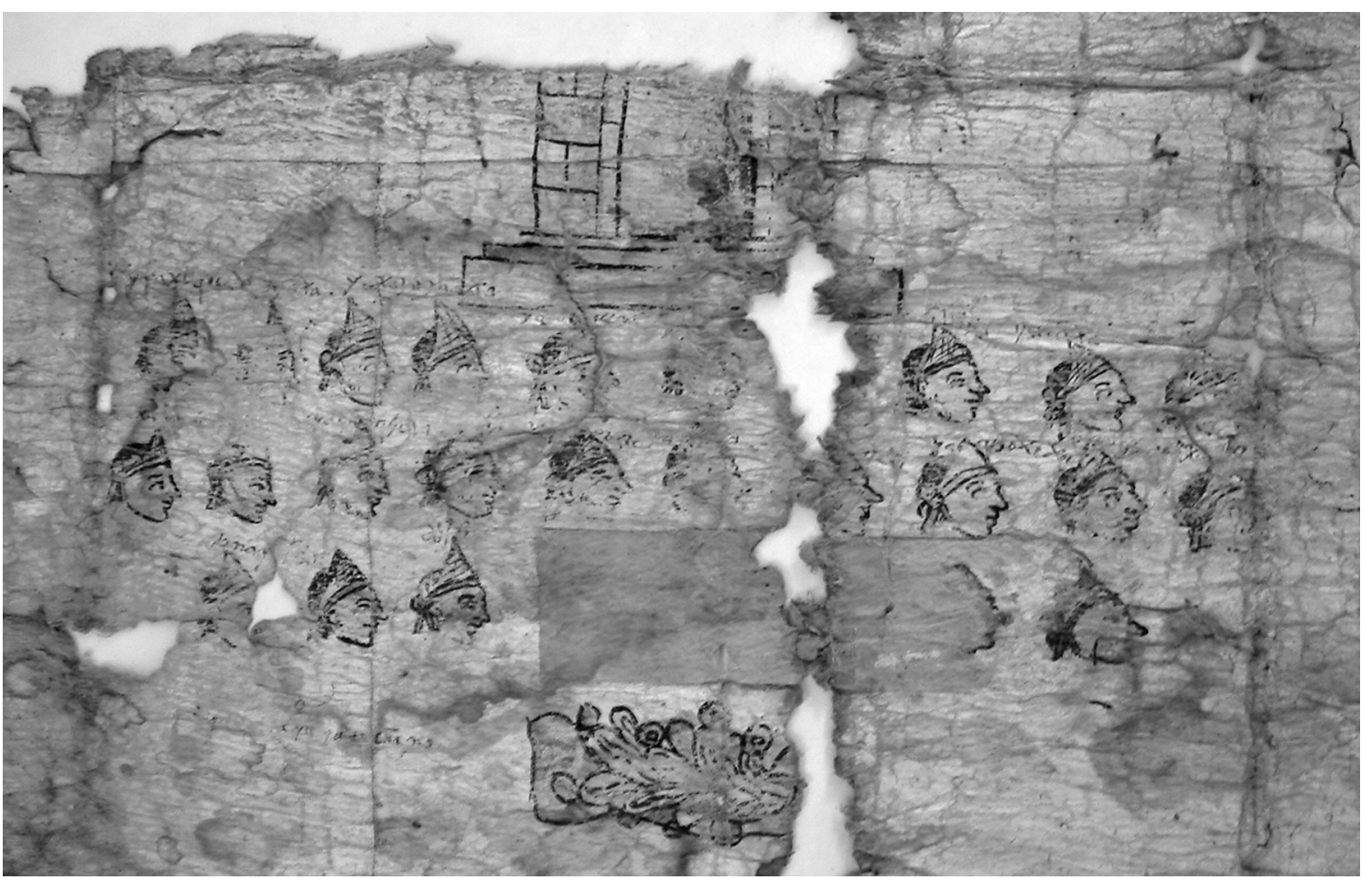

Figura 3. La lista de yya en el señorío superior del Lienzo de San Vicente el Palmar. 


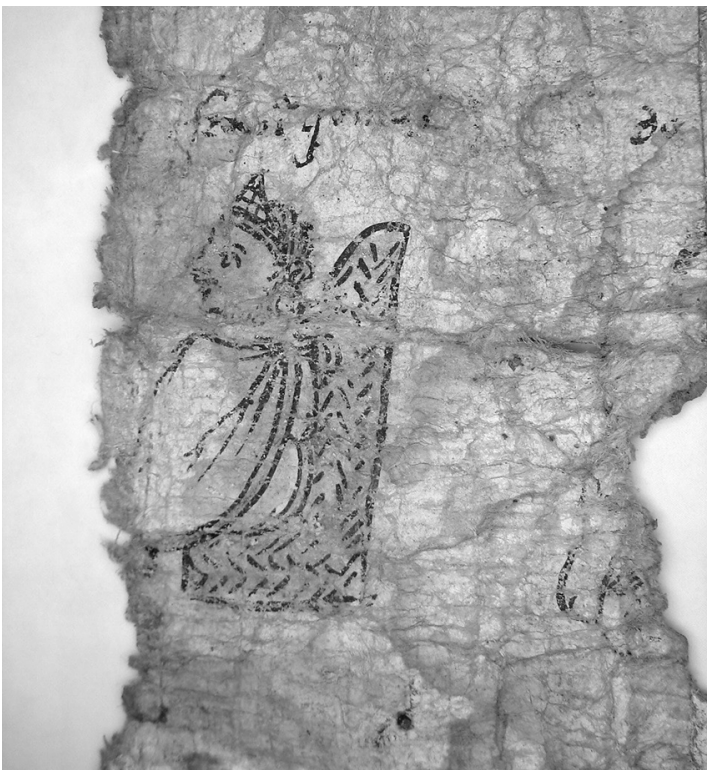

Figura 4. El gobernante don Francisco Gómez en la parte superior del Lienzo de San Vicente el Palmar.

102 tes en el paisaje para demarcar terrenos. Desafortunadamente, estas plantas no nos pueden ayudar a identificar las zonas delimitadas. Sin embargo, entre las plantas, magueyes y nopales aparece también un topograma con características específicas, el cual representa un cerro con tortillas en su interior y que lleva la glosa yucu dzita ('cerro de tortillas') (fig. 6).

Para avanzar en la interpretación del documento es importante identificar a los señoríos representados en ellos ${ }^{20}$. En otras palabras, el análisis avanzado del contenido está condicionado a la identificación del lugar de origen del documento. Cuando un documento se conserva en la comunidad de origen, como es el caso de, por

\footnotetext{
${ }^{20}$ La Mixteca estaba dividida en una serie de comunidades-territorios llamados ñu que, al interior, se caracterizaban por una fuerte integración política y una identidad compartida. Para indicar el gobierno de una casa real sobre tal $\tilde{n} u u$, los mixtecos usaron el término yahuitayu. Los territorios representados por medio de rectángulos de linderos en los lienzos los interpreto como dibujos del yuhuitayu, sobre todo por la presencia de gobernantes en su interior. Esto no se debe confundir con las tierras patrimoniales pertenecientes a la casa real ubicadas dentro del yuhuitayu/ñuu.
}

ejemplo, el Lienzo de Tequixtepec, esto por lo general no presenta problemas. Sin embargo, se vuelve complicado cuando el documento fue removido de su comunidad de origen y se halla en otra comunidad (por matrimonios, muertes inesperadas, etc.) o en un instituto académico o museo (por robo, expropiación, presión política, traslado o compra-venta). En algunos casos, el rastreo de la historia del documento descontextualizado — siempre que sea posible - puede arrojar pistas para identificar lo representado en él21. Ahora, a pesar de que el Lienzo de San Vicente el Palmar se conserva en una comunidad oaxaqueña de la Mixteca Baja, la poca importancia histórica de esta comunidad y su aparente reciente historia ponen en duda que éste haya sido su lugar de origen ${ }^{22}$. La identificación del lugar de origen de un documento descontexualizado puede lograrse por medio del hallazgo de la documentación alfabética relacionada directamente con el documento o de la identificación de un conjunto interrelacionado de topogramas (por ejemplo, una serie de linderos) o de algún nombre de un gobernante del documento pictórico en otro documento antiguo, o sea, que la identificación se logra por medio de la comparación entre el documento pictórico y la documentación alfabéti$\mathrm{ca}^{23}$. Para ser más específicos, se busca establecer correlaciones entre: 1) los elementos de los topogramas (a veces con glosas) representados en la pictografía y los topóni-

\footnotetext{
${ }^{21}$ Un buen ejemplo es el Códice Porfirio Díaz, actualmente en la Biblioteca Nacional de Antropología, el cual, por medio de la reconstrucción de su historia de adquisición, fue identificado como un documento de San Francisco Tutepetongo, Oaxaca. Son varios los casos en que documentos han mudado de una comunidad a otra, p.e. el Rollo de Tulane (de Acatlán a San Juan Numi y de allí a la Universidad de Tulane, véase Smith y Parmenter, 1991) y el Lienzo de Tulancingo (de Ihuitlán a Tulancingo, véase Doesburg, 2000).

22 Por razones obvias, los documentos — sobre todo los más complejos- suelen estar relacionados con comunidades de importancia política. La primera referencia que conozco a un San Vicente sujeto de Tonalá es de 1643 (AGN, Vínculos, vol. 69, exp. 1lbis, f. 152v). En 1890, las autoridades de la población declararon que ellos eran arrendatarios de San Agustín Atenango, por haber comprado este último pueblo - a mediados del siglo XIX- los terrenos del descendiente de la cacica doña Isabel Terrazas (AGEO, Conflictos, leg. 75, exp. 2). La búsqueda de San Vicente durante el siglo XX del reconocimiento de su territorio ha resultado en una relación conflictiva con San Agustín.

${ }^{23}$ Una descripción del método para la identificación de lugares se en-
} cuentra en Doesburg (2001a: 145-148). 


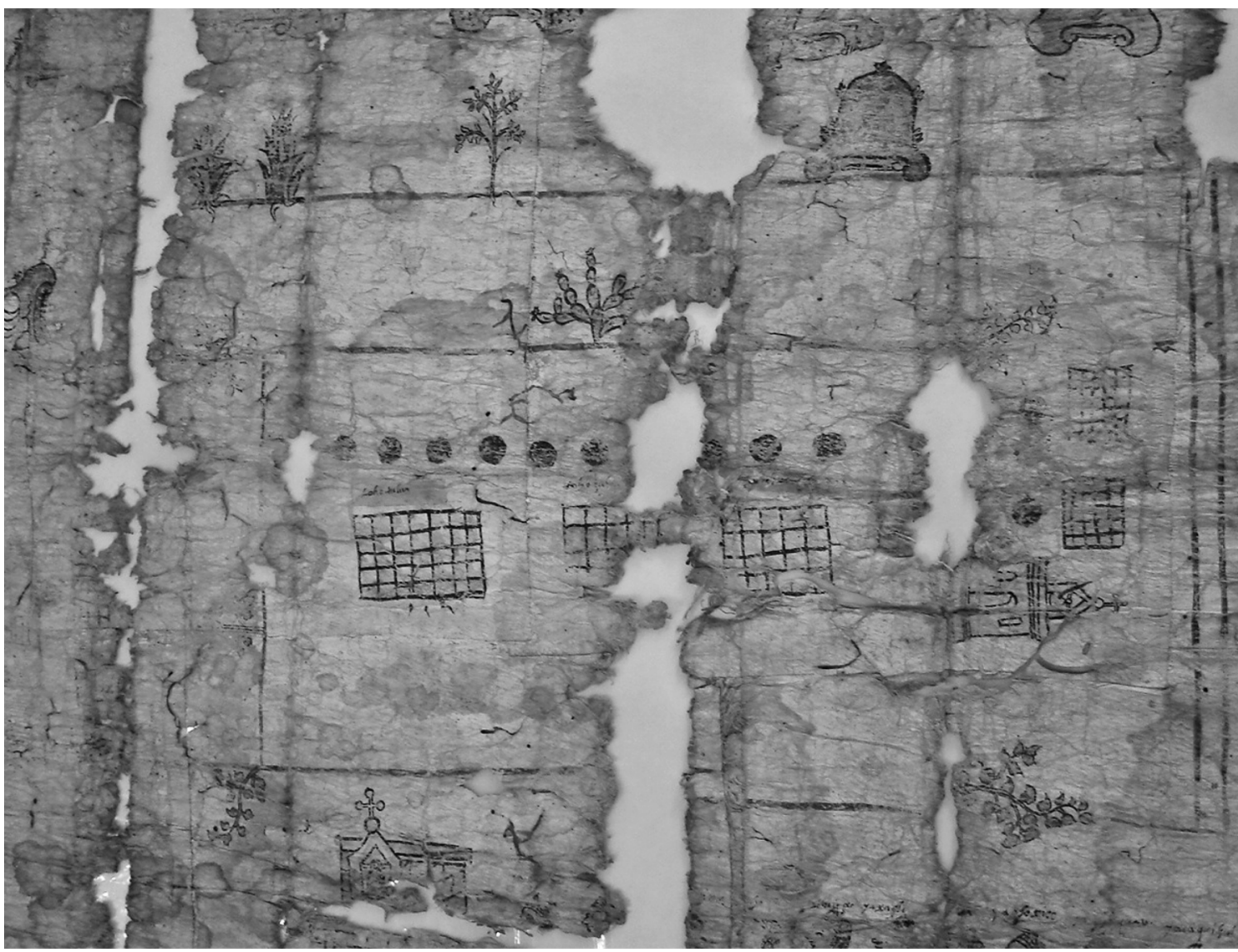

Figura 5. El área delimitada en el señorío inferior del Lienzo de San Vicente el Palmar.

mos en las fuentes históricas o existentes en la actualidad — como ya se dijo, los rectángulos de linderos en los lienzos conforman una variante de este tema-; 2) (sólo en representaciones cartográficas) la geografía representada en el documento pictórico y la distribución de los lugares en la actualidad; 3) la prominencia política o religiosa de una comunidad en el relato pictórico y la importancia histórica de un pueblo o sitio según las fuentes históricas; 4) las relaciones políticas, genealógicas, tributarias, etc., entre pueblos representadas en la pictografía y las relaciones registradas en las fuentes históricas; y 5 ) las personas representadas en la pictografía y personas mencionadas en otras fuentes históricas. En la medida en que una propuesta va cubriendo más de las condiciones mencionadas, la identificación se hace más segura.

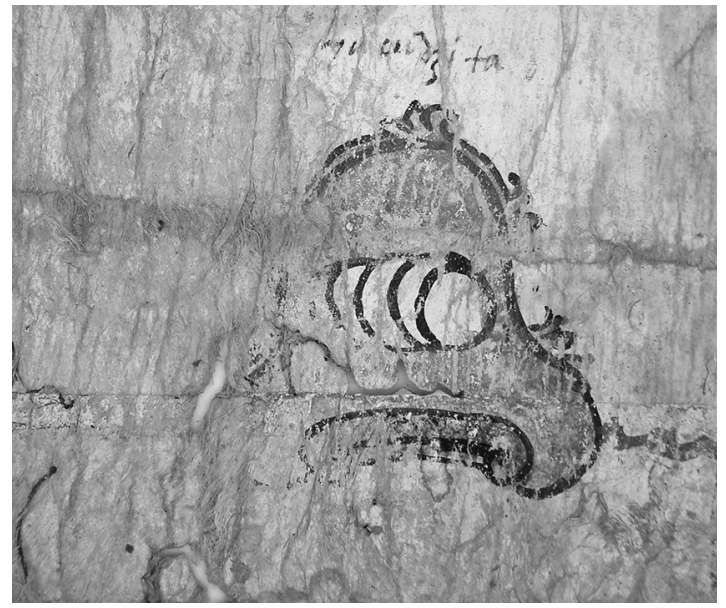

Figura 6. El Cerro de Tortillas (yucu dzita) en la orilla del área delimitada. 


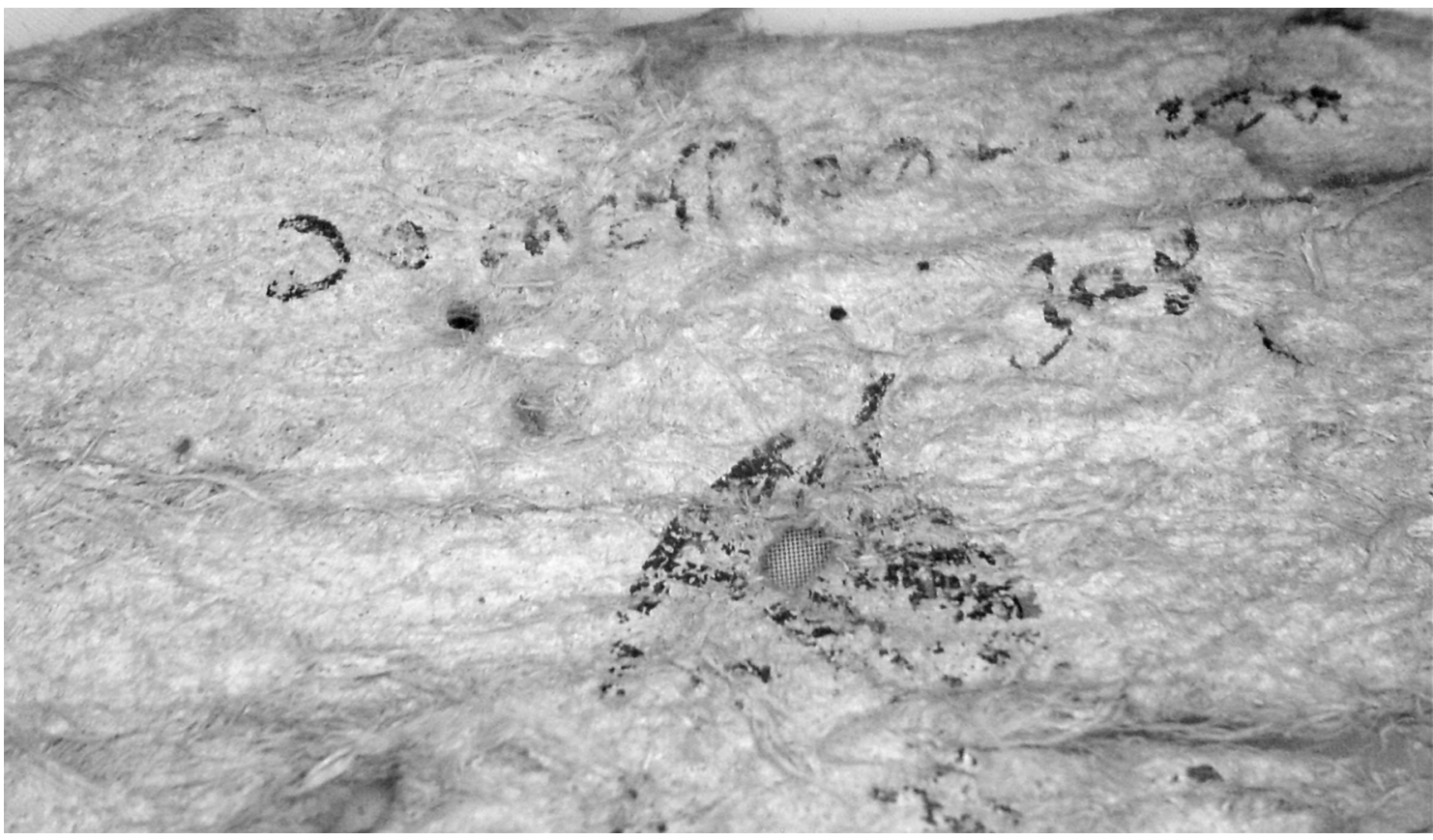

Figura 7. La glosa que identifica a don Carlos de Terrazas en la lista de los yya en el señorío inferior del Lienzo de San Vicente el Palmar.

La falta de papeles relacionados directamente con el lien$\mathrm{zo}^{24} \mathrm{y}$ los daños al documento mismo parecen brindar pocas esperanzas, pero, por fortuna, hay en el lienzo algunas glosas, apenas legibles, que nos dan las pistas necesarias. El uso de las glosas explicativas en el estudio de los documentos pictóricos ha sido muy productivo y, de hecho, constituye la base para la mayor parte de los 'desciframientos' (i.e. identificación de topogramas y personas) realizados hasta ahora. Sin embargo, es necesario establecer primero si las glosas pertenecen al mismo estrato que la pintura o forman parte de una 'reinterpretación' o disyunción iconológica del documento ${ }^{25}$. En el caso del Lienzo de San Vicente, el estilo de las letras y la concordancia consistente entre glifos y glosas en el documento,

\footnotetext{
${ }^{24}$ Existe en el pueblo de San Vicente el Palmar un expediente tardío (quizás del siglo XVIII) que contiene copias de diversos documentos relacionados con los cacicazgos de Ihualtepec y Mixtepec, pero no se ha encontrado una relación directa con el contenido del lienzo.

25 Para la problemática de las glosas 'disyuntivas', véanse Smith, 1973: 57; Smith y Parmenter, 1991; y Doesburg, 2001b.
}

tanto en los topogramas como en los nombres, indican que las glosas pertenecen al estrato pictórico original ${ }^{26}$.

Arriba del gobernante que encabeza el linaje de gobernantes en la parte inferior del lienzo se distingue una glosa muy destruida que dice do ca(rllos) de terrazas (fig. 7). Este apellido poco común perteneció al linaje de los caciques de Yoaltepec (hoy San Juan Ihualtepec) desde mediados del siglo XVI hasta bien entrado el XIX27. El nom-

\footnotetext{
${ }^{26}$ El caso contrario sucede con la copia de este lienzo en la Reforma Agraria. Las glosas puestas en este documento junto a los topogramas no se relacionan con los topogramas copiados fielmente del original, sino que reproducen los linderos de San Vicente el Palmar. Éste es un claro caso de 'reinterpretación' del documento con el objetivo de usarlo como prueba en un juicio agrario. Por ejemplo, la glosa Yucuñotica ('cerro partido') fue cambiada a Tucuititunyin, que aparece en una lista de linderos en el archivo de la actual población. (Una lista de los linderos de San Vicente aparece en AGN, Vínculos, vol. 69, exp. 11bis, f. 156.) ${ }^{27}$ El apellido viene sin duda del conquistador Francisco de Terrazas, quien fue encomendero de la mitad de Ihualtepec. El padre de don Carlos se llamó don Juan de Aguilar. Este apellido fue tomado del encomendero de la otra mitad de Ihualtepec, García de Aguilar. Para los caciques de Ihualtepec con apellido de Terrazas, véanse p.e.: AGN, Tierras, vol. 85, exp. 2, 1623-1674; Tierras, vol. 494, exp. 5, 1730; Tierras 1262 , exp. 1,1781 .
} 
bre Carlos corresponde a un gobernante del cacicazgo de Ihualtepec activo en la segunda mitad del siglo XVI y que aparece en varios documentos del Archivo General de la Nación ${ }^{28}$ y en la llamada Genealogía de Igualtepec de 1578, ya mencionada más arriba. Por lo tanto, parto ahora de la hipótesis de que el Lienzo de San Vicente el Palmar representa, en su mitad inferior, al señorío de Ihualtepec, y no a Tonalá, como pensó Smith.

Durante la época Posclásica Yoaltepec era un señorío de importancia. Según fuentes mexicas, fue conquistado durante el reinado de Moctezuma I (1440-1464) ${ }^{29}$. La Matrícula de Tributos menciona Yoaltepec como cabecera de una pequeña provincia tributaria (fig. 8). Distintas fuentes del siglo XVI sugieren que el señorío —entidad distinta a la provincia tributaria — o, por lo menos, el área de su jurisdicción, era grande. Un documento de finales del siglo XVI (1598) enumera "los pueblos de la cabecera de Ygualtepec" 30 . Los he puesto en un mapa para indicar el territorio cubierto por estos pueblos (mapa 2, p. 106) ${ }^{31}$.

En la nómina de los pueblos sujetos llaman la atención los dos pueblos de salinas mencionados al principio de la lista: San Bartolomé Xoxouqui Iztapan ('salinas verdes') y San Pedro Cuezcoma Iztapan ('salinas del coscomate') ${ }^{32}$. Su posición en el listado se debe quizás a su importancia económica para el señorío. La sal era un producto muy valioso que se comercializaba en una extensa región ${ }^{33}$. Hasta hoy día, estos dos pueblos, junto con Santa María y San Ildefonso, siguen produciendo sal de acuerdo con los métodos prehispánicos (fig. 9, p. 106) ${ }^{34}$. La antigüedad de la producción de sal es evidente: por ejemplo, en

28 P.e.: Indios, vol. 1, exp. 111, 1577; General de Parte, vol. 2, exp. 278, 1579 y exp. 735, 1580; Jesuitas, Caja I-14, exp. 448, f. 2081, 1588; Indios, vol. 6, exp. 120, 177 y 296, 1592 (en este año ya difunto).

${ }^{29}$ Anales de Cuauhtitlán, 1975, p. 238.

${ }^{30}$ AGN, Tierras, vol. 2809, 2a parte, exp. 22.

${ }^{31}$ Otra lista de los pueblos del cacicazgo de Ihualtepec del siglo XVIII (1723) describe aproximadamente la misma extensión (AGN, Tierras, vol. 494, exp. 5).

${ }^{32}$ Estas mismas salinas aparecen en AGN, Mercedes, vol. 23, f. 14, 1599, en un 'acordado' para ver un sitio de estancia para ganado menor.

33 En la Relación Geográfica de Justlahuaca (Acuña, 1984: 290) se menciona la sal de Tonalá y Yoaltepeque. Para un panorama general de la importancia de la sal en el México indígena, véase Ewald, 1985.

${ }^{34}$ Carlos Viramontes (1993) hizo un muy útil estudio de la actual producción de sal en estos pueblos.

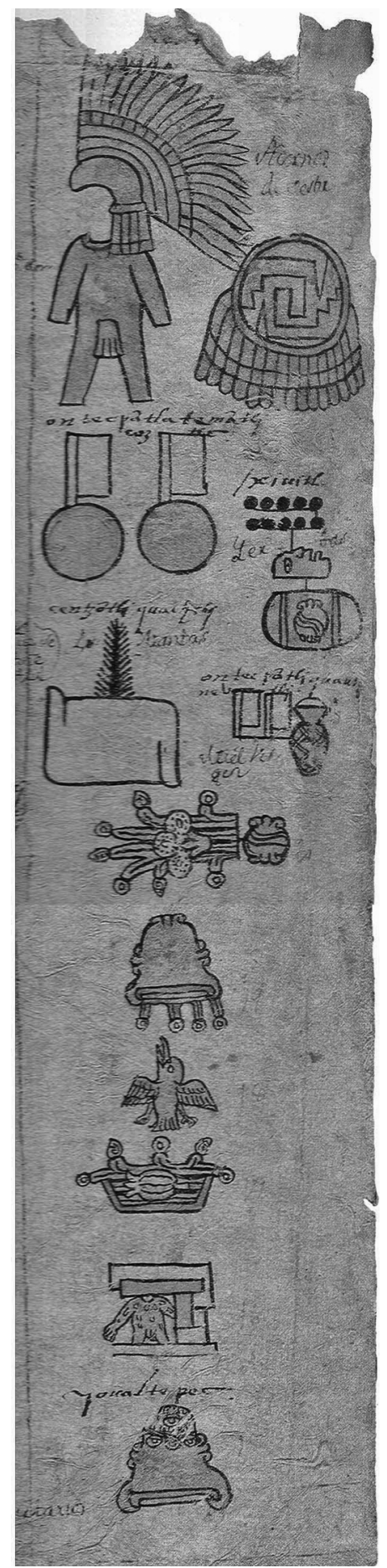

$>105$

Figura 8. La provincia tributaria de Yoaltepec en la Matrícula de Tributos. 


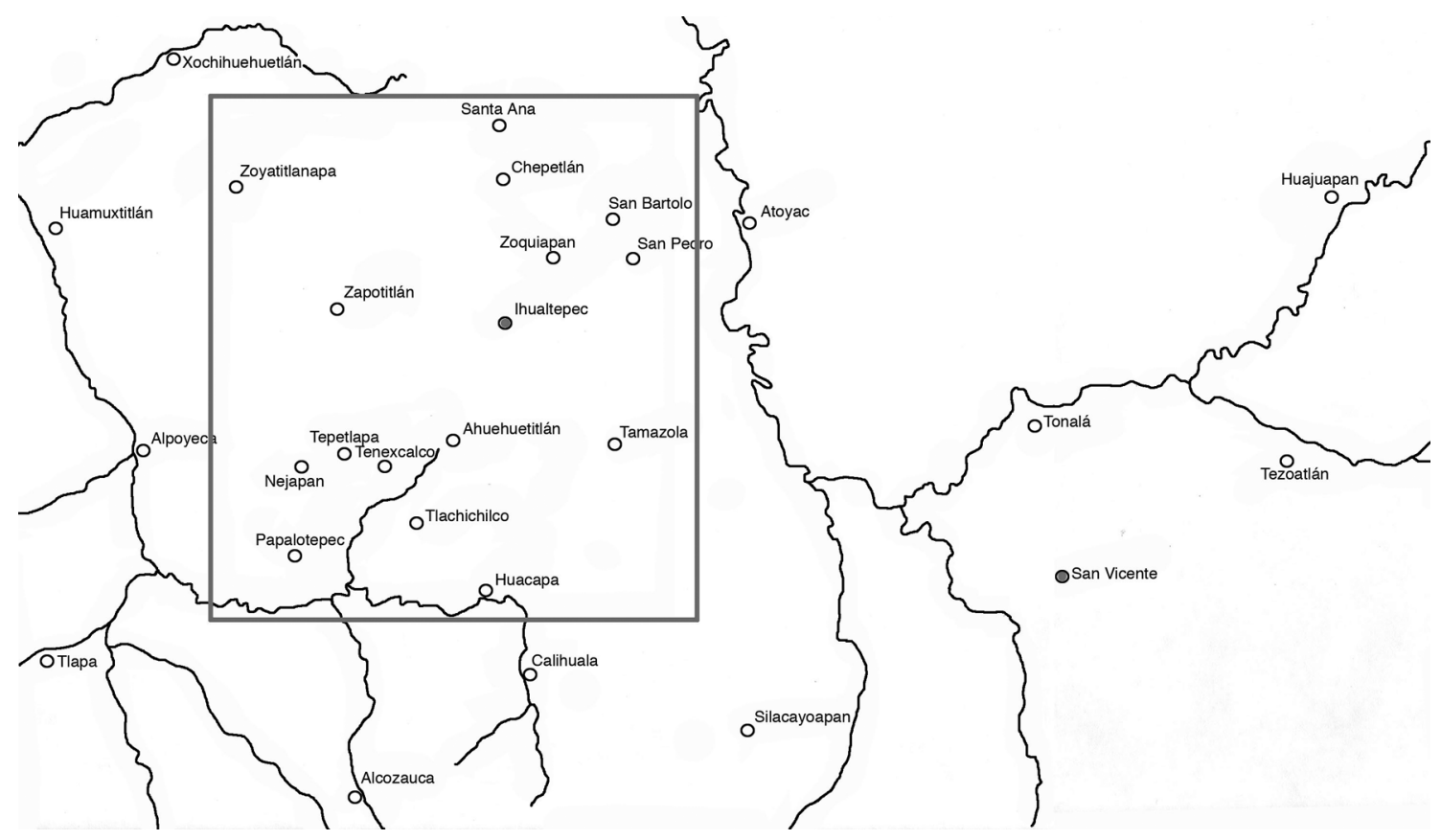

Mapa 2. La cabecera de Ihualtepec y sus sujetos en el siglo XVI.

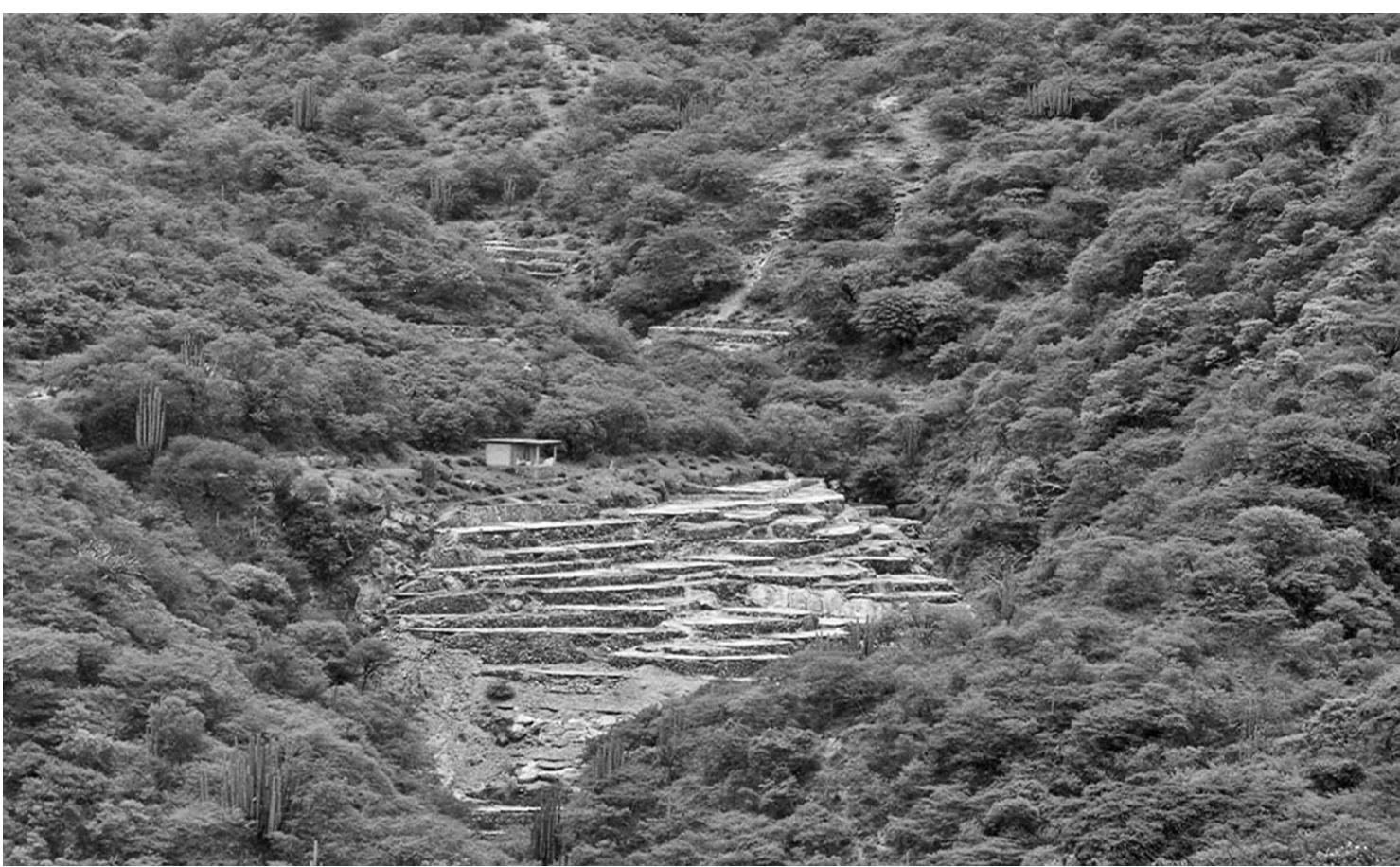

Figura 9. Las fincas de sal de Santa María. 


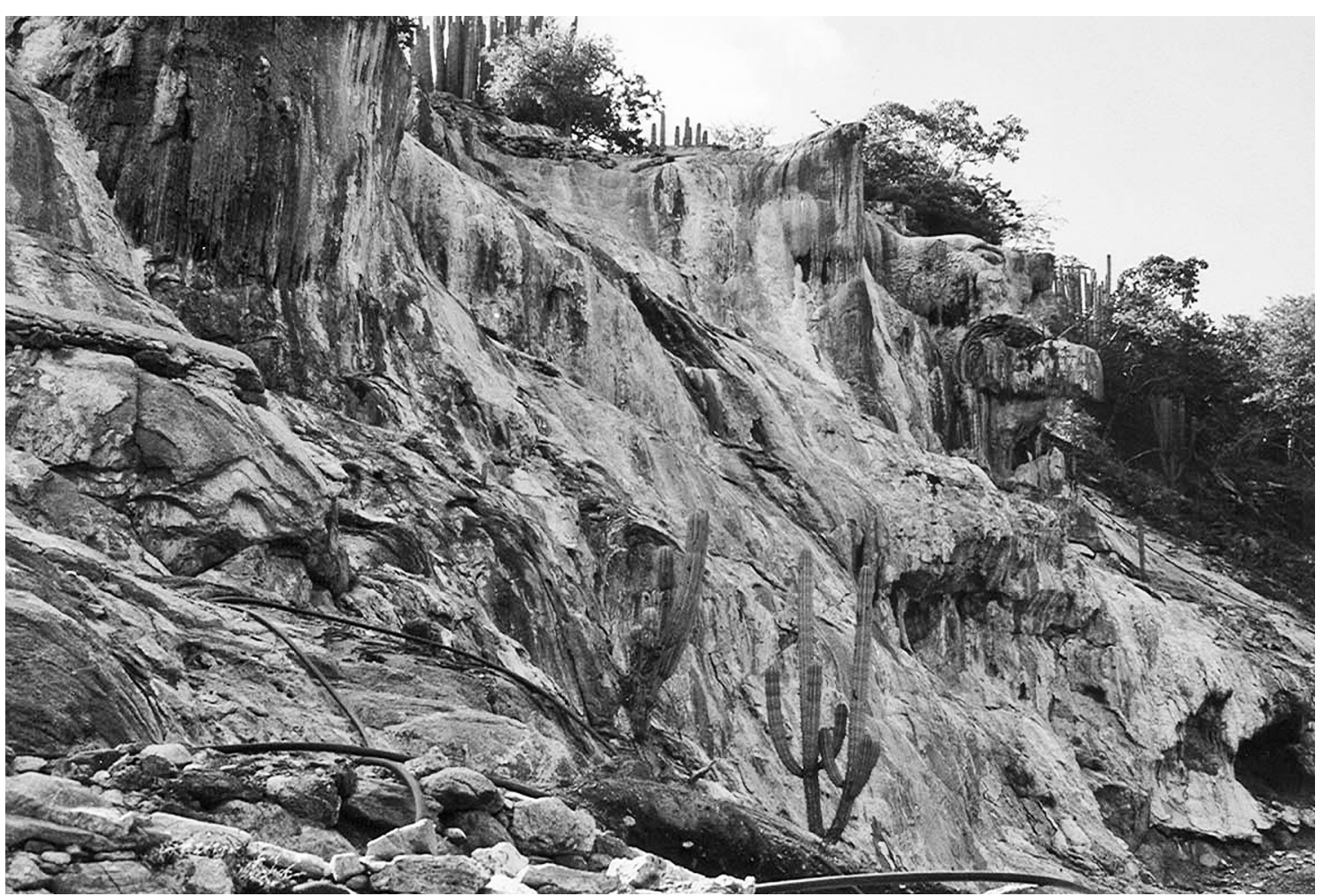

Figura 10. Depósitos de minerales en las fincas de sal de San Bartolo.

San Bartolo, un sitio arqueológico corona el espectacular paisaje surrealista de los manantiales salados y sus depósitos de minerales (fig. 10) ${ }^{35}$.

La visita a la geografía representada en los documentos es de gran utilidad y ayuda en la identificación de los elementos dibujados; de hecho, debe ser parte integral del método para la investigación de los documentos pictóricos. En este caso, la disposición de las filas de cajetes en las actuales fincas de sal (fig. 11, p. 108) me recordó los rectángulos subdivididos en cuadritos dibujados en el Lienzo de San Vicente el Palmar ${ }^{36}$. En un mapa del siglo XVIII

\footnotetext{
${ }^{35}$ De hecho, hasta la Revolución, las fincas de sal de San Bartolo pertenecieron a don Porfirio Vidal de Ihualtepec, posiblemente un descendiente de los caciques de aquel lugar (comunicación personal de doña Andrea de San Bartolo).

${ }^{36}$ La representación es muy similar a los rectángulos dibujados en el Lienzo de Coixtlahuaca II (o Seler II), los cuales identifiqué anteriormente (Doesburg, 2003: 77) como tierras y que ahora pienso que re-
}

del pueblo cercano de Chila de la Sal, las fincas de sal están dibujadas de manera idéntica (fig. 12, p. 108). Por lo anterior, destaco aquí que estos rectángulos representan fincas de sal. Esta identificación se refuerza por la localización del Cerro de las Tortillas, que en la actualidad aún lleva este nombre, muy cerca de las fincas de sal de San Ildefonso y San Pedro (mapa 3, p. 109). De esta lectura geográfica se concluye que la parte superior del lienzo está orientada hacia el oriente — la salida del sol—, un hecho común en los lienzos de Oaxaca.

La prominente inclusión de estas fincas de sal en el territorio de Ihualtepec y las líneas rojas divisorias relacionadas con ellas hacen suponer que el lienzo podría tratar de un acuerdo o arreglo sobre la distribución de las

presentan fincas de sal en las orillas del río Calapa, donde, de hecho, se producía sal durante el siglo XVI y se sigue produciendo el día de hoy. 


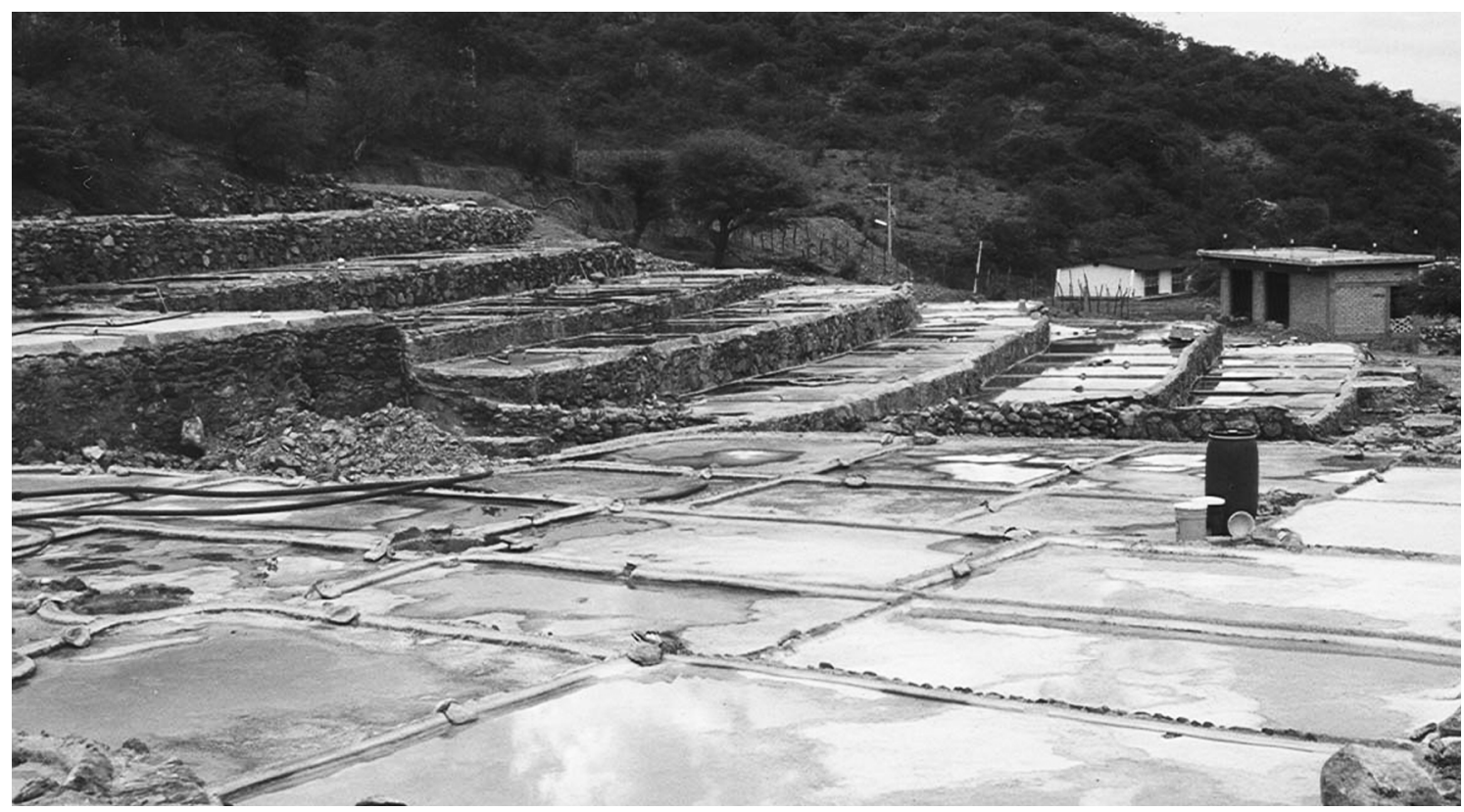

Figura 11. Las fincas de sal de San Ildefonso.

$108<$

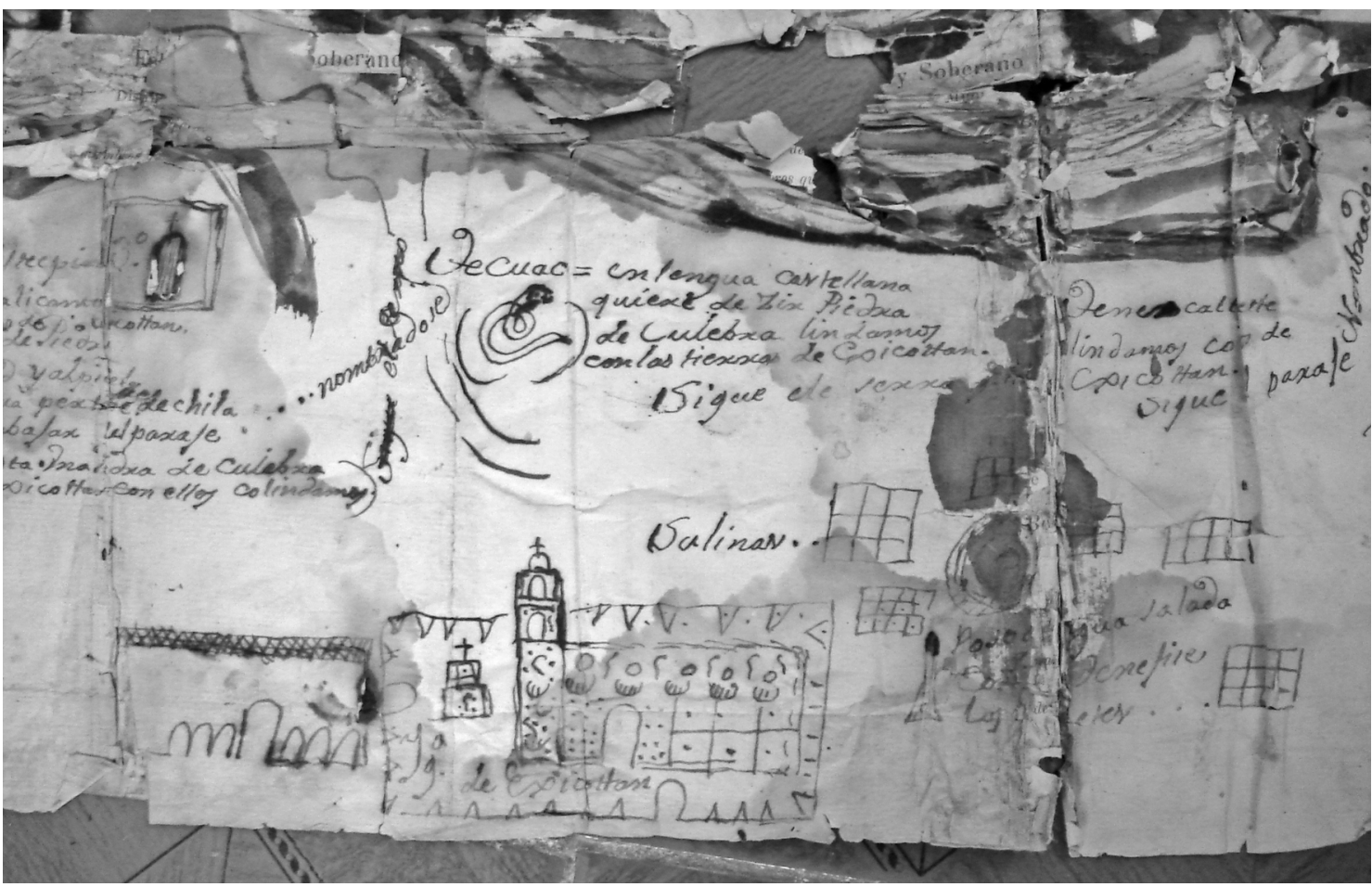

Figura 12. Salinas y un pozo de agua salada representados en un mapa colonial de Chila de la Sal, Puebla. 


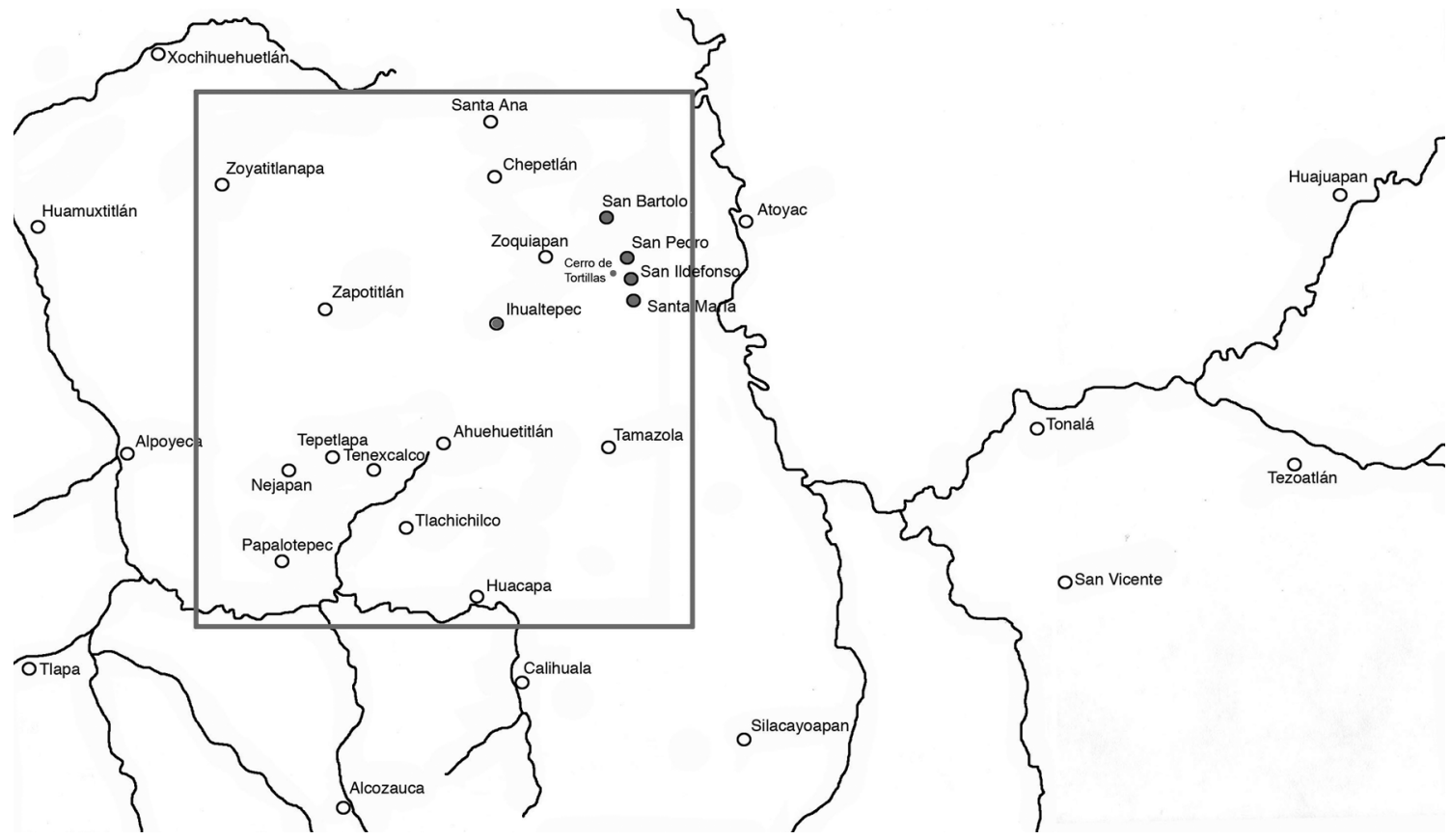

Mapa 3. Ubicación de las salinas y el Cerro de Tortillas en el territorio de Ihualtepec.

salinas mencionadas entre Ihualtepec y el señorío representado en la parte superior del lienzo. De hecho, algunos documentos históricos indican que las salinas de esta zona eran el objeto de pleitos durante el siglo XVI. Unos documentos tardíos existentes en San Vicente hacen una brevísima referencia a un pleito sobre salinas alrededor de 1583 entre, por una parte, don Carlos de Terrazas y su esposa Inés Gómez de Tonalá y, por la otra, doña María de Sosa y don Juan de Santiago de Tonalá. Luego, en 1592, un pretendiente al señorío de Ihualtepec se quejó de que el hermano de don Carlos, don Diego de Terrazas, se había quedado con "el señorío y cacicazgo y con unas salinas, tierras y joyas"37.

¿A qué pleito, o mejor dicho, acuerdo sobre salinas se refiere el Lienzo de San Vicente el Palmar? La identificación del señorío representado en la parte superior no se puede lograr por medio del nombre del gobernante que encabeza el grupo debajo de la iglesia, ya que la glosa sola-

${ }^{37}$ AGN, Indios, vol. 6, exp. 120. mente nos da el nombre don Juan (fig. 13, p. 110). La falta de un apellido nos imposibilita identificar a este señor en los documentos del siglo XVI. Sin embargo, debajo de la cabeza de don Juan se ve un topograma semidestruido que consiste en un valle del cual brota un chorro de agua. Al lado se encuentra una glosa casi ilegible cuya última parte se puede leer como [...] tayu yuta caánu, 'señorío del río grande' (fig. 14, p. 110). Este es el nombre mixteco de San Pedro Atoyac, hoy una pequeñísima comunidad de apenas 400 habitantes, pero que en el siglo XVI era un señorío colindante con Ihualtepec por el oriente y ubicado en las márgenes del río Mixteco ${ }^{38}$. Los registros coloniales sugieren que este señorío estaba relacionado con el de Tonalá39. Si proyectamos las identificaciones propuestas en este trabajo en un mapa actual

$38 \mathrm{El}$ nombre aparece en la lista de topónimos de fray Antonio de los Reyes, en su Arte en lengua mixteca (1593). No se debe confundir este San Pedro Atoyac con el pueblo del mismo nombre en la provincia de Jicayán. Véase también Gerhard, 1986: 131 (Guaxuapa) y 389 (Xicayán). ${ }^{39}$ En el Libro de Tasaciones, 1952, p. 525, Atoyac está incluido en la tasación de Tonalá. 


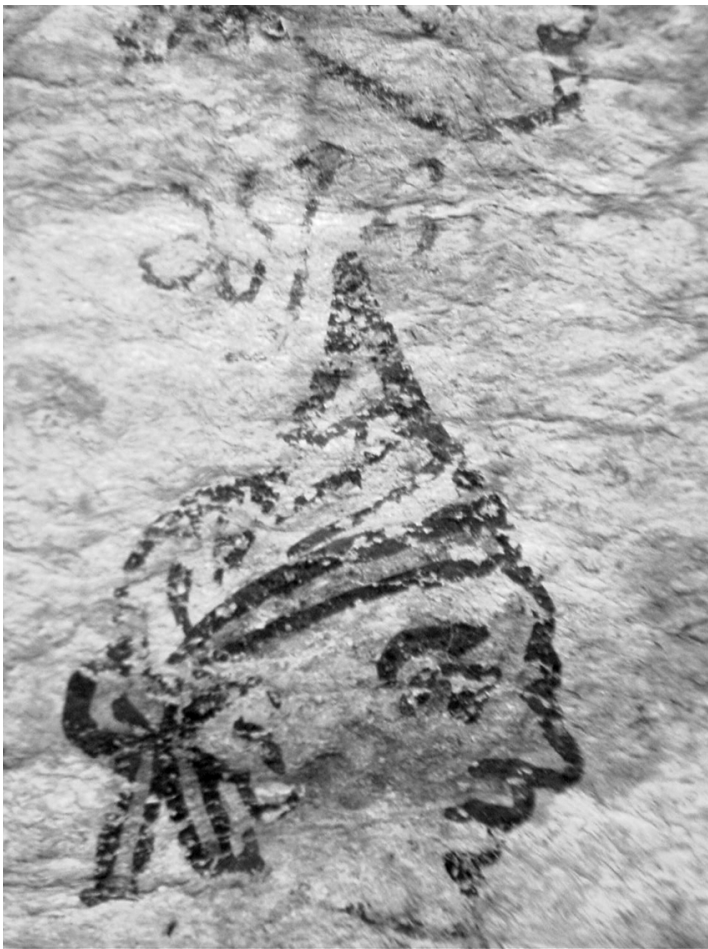

110
Figura 13. La cabeza de don Juan con su glosa en el Lienzo de San Vicente el Palmar. (mapa 4, p. 112), se nota la coincidencia con la composición general del Lienzo de San Vicente el Palmar. Por lo mismo, parto de la idea de que el señorío en la parte superior del lienzo representa a San Pedro Atoyac. Esta hipótesis deriva en otra: la relación espacial entre el Cerro de Tortillas y las salinas (mapa 4, p. 112) sugiere que se trata de las fincas de Santa María (la capilla a la derecha) y San Ildefonso (la capilla a la izquierda). Éstas son las dos salinas no incluidas en la antes mencionada lista de 1598, lo cual es quizás significativo: San Pedro y San Bartolo parecen haber sido parte indiscutible del señorío, pero sobre Santa María y San Ildefonso pudo haber existido alguna duda. Cada capilla o población está asociada a dos fincas de sal. Las tres fincas de sal en el centro podrían representar fincas pertenecientes a los nobles (ide Ihualtepec?), ya que las glosas asociadas con ellas comienzan con toho, que es la palabra para 'noble' (fig. 15). Así se entiende la ausencia de una capilla relacionada con estas fincas. Los puntos negros asociados con las fincas podrían indicar el número de manantiales salados que las abastecen o podrían representar alguna medida de su productividad.

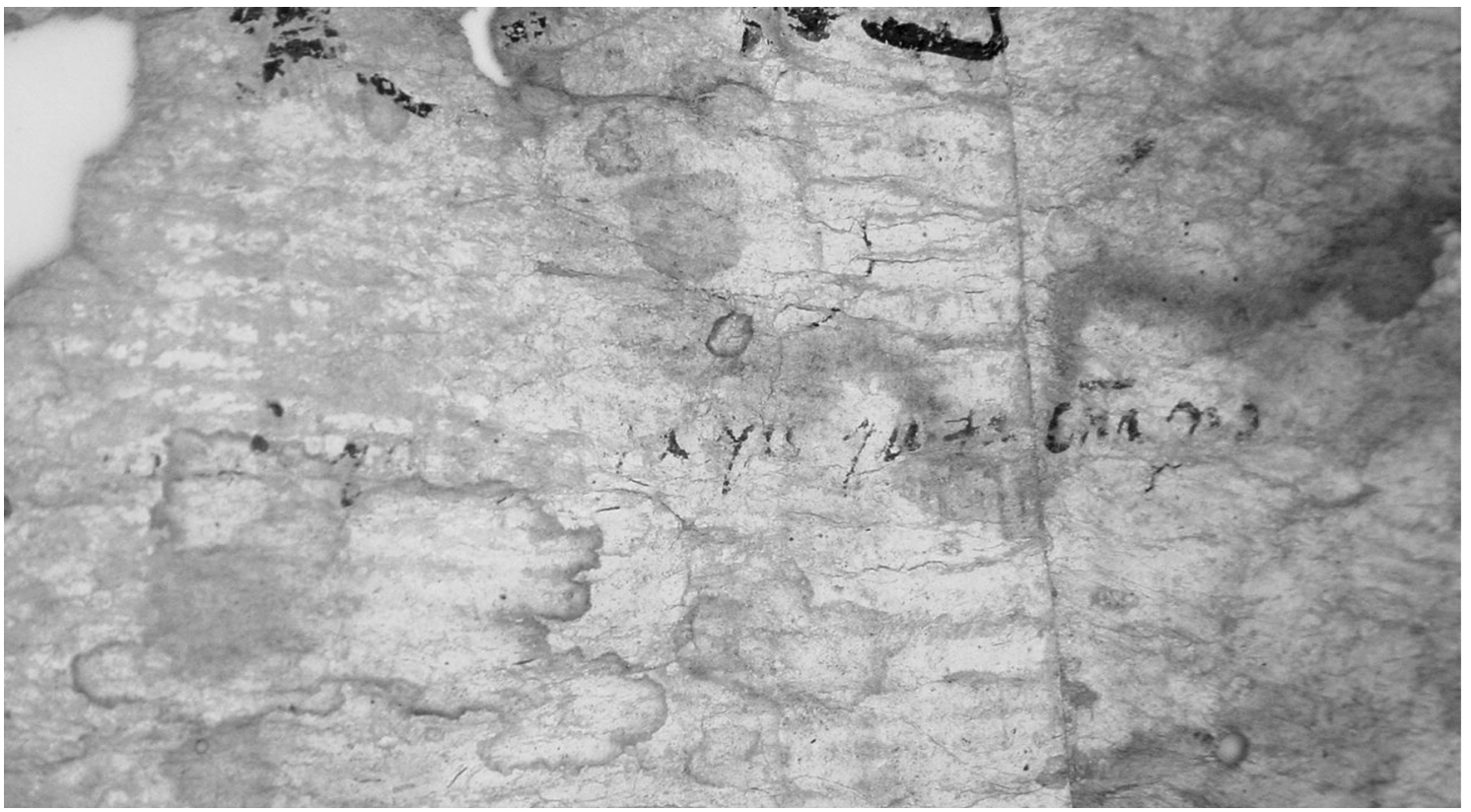

Figura. 14. La glosa que contiene el nombre mixteco de San Pedro Atoyac. 


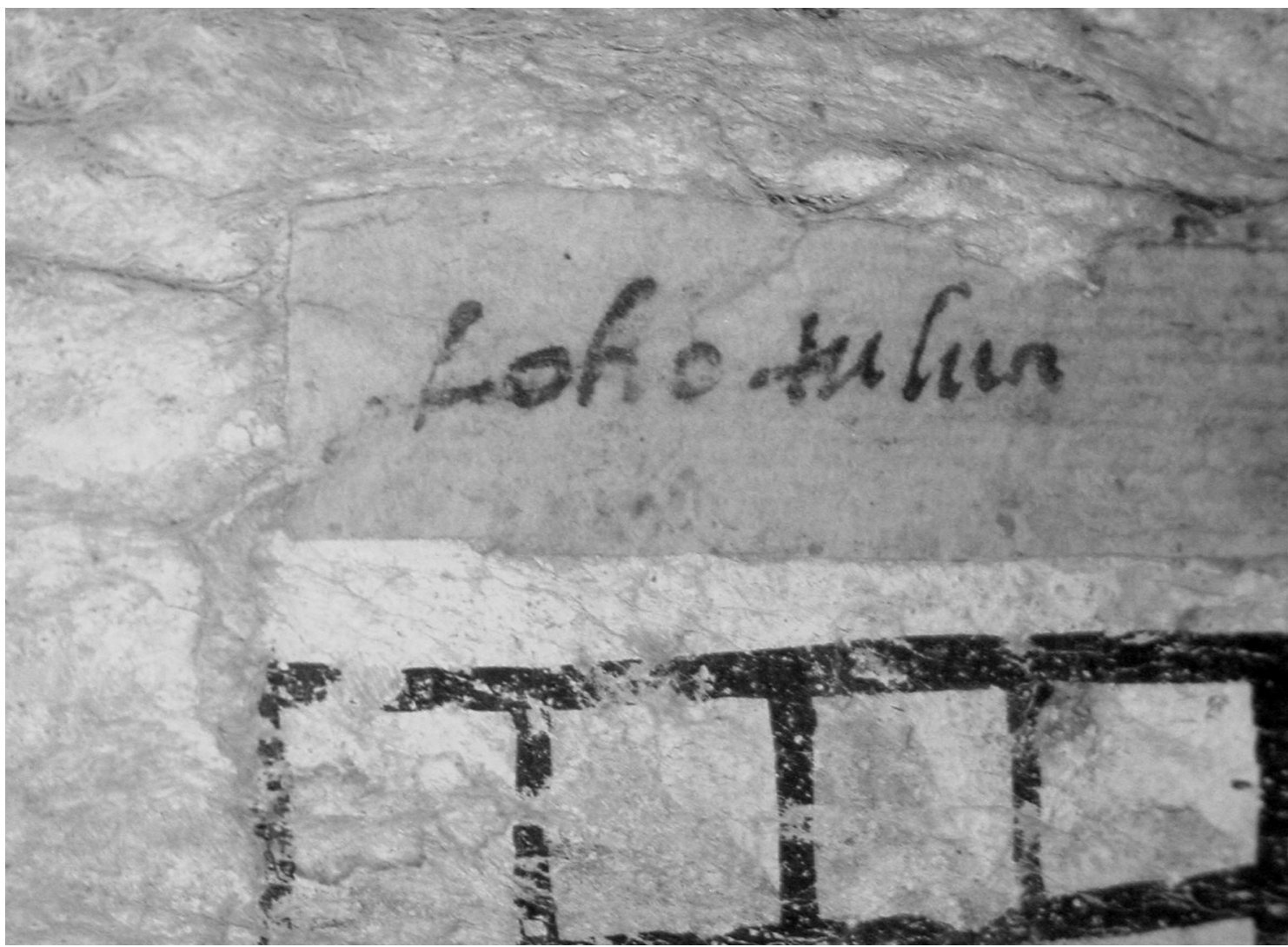

Figura 15. Las glosas que acompañan las tres fincas de sal en el centro del Lienzo de San Vicente el Palmar contienen la palabra toho, 'noble'.

Para confirmar definitivamente estas identificaciones, regresamos al gobernante sentado en un trono en la parte superior del lienzo: don Francisco Gómez. Un documento del siglo XVI, publicado por Guillermo Fernández de Recas en 1961, identifica a éste como el cacique de Tonalá y padre de Inés Gómez, quien fue la mujer de don Carlos de Terrazas (Fernández de Recas, 1961: 201-209). De hecho, su posición en la parte superior del lienzo (o sea, en el oriente) coincide con la ubicación aproximada de Tonalá (véase mapa 2, p. 106) ${ }^{40}$.

\footnotetext{
${ }^{40}$ La mujer, apenas visible sentada detrás de don Francisco Gómez, podría ser su hija doña Ana Gómez, esposa de don Miguel de Guzmán I, caciques de Tonalá después de la muerte de don Francisco (Fernández de Recas, 1961: 203). En 1565, doña Ana ya es viuda. Sin embargo, un don Miguel de Guzmán II aparece como cacique de Tonalá en las décadas
}

Según los documentos mencionados, entre 1581 y 1585, don Carlos de Terrazas, en representación de su fallecida esposa Inés, sostuvo un pleito con don Juan de Santiago, quien, a su vez, representaba a su esposa, otra hija de don Francisco Gómez, llamada doña María de Sosa. El

de 1580 y 1590, p.e. AGN, Tierras, vol. 2726, exp. 1 (1594). Este don Miguel heredó de doña María de Sosa (también llamada de Villagómez o Gómez) el cacicazgo con cuatro salinas y "demás ojos de agua salada" (Fernández de Recas, 1961: 209). En otro texto (AGN, Indiferente Virreinal, caja 6596, exp. 39, 1584) se dice que "don Miguel de Guzmán, gobernador, cacique y natural de ese dicho pueblo de Tonalá $[. .$.$] me$ hizo relación diciendo que al tiempo que doña María Gómez, su tía, cacica que había sido del dicho pueblo, había pasado de esta presente vida le había dejado por su universal heredero en todos sus bienes muebles y raices, ojos de agua salada que se nombraban Talistacapan y en otros declarados y nombrados en su testamento de su patrimonio y mayorazgo". 


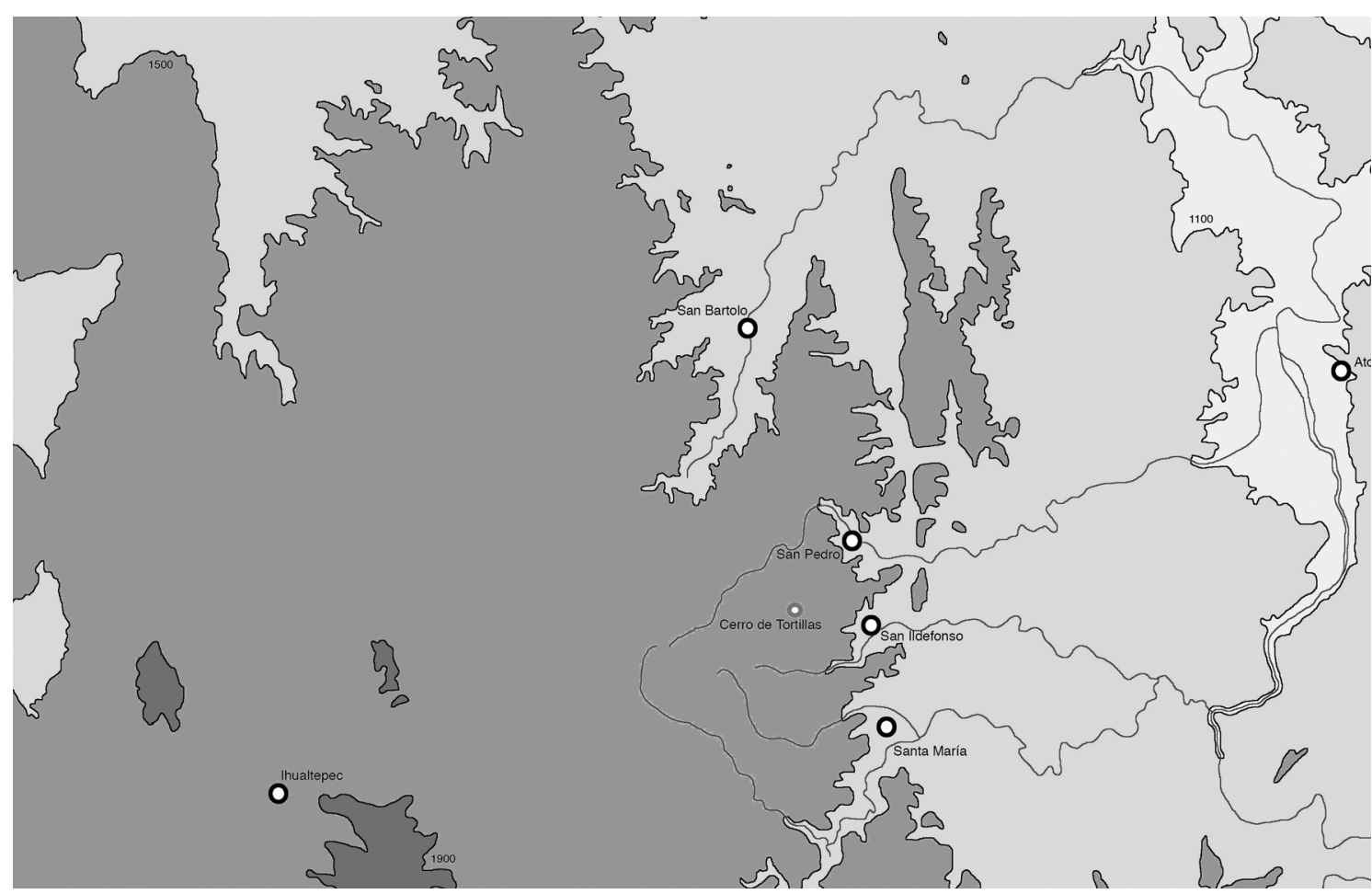

Mapa 4. La zona de las salinas entre Ihualtepec y Atoyac con indicación de alturas. Todas las salinas están justo abajo de los 1500 msnm.

pleito entre los concuños trató sobre la herencia de don Francisco Gómez (véase esquema 2), que incluía las salinas que hemos comentado antes y que se describen como "mucha hacienda, muchas sementeras e casas e tunales de grana y muchas suertes de piletes en que se cuaja la sal". Por lo tanto, supongo ahora que el don Juan que aparece como señor de Atoyac en el lienzo es don Juan de Santiago, el concuño de don Carlos de Terrazas ${ }^{41}$.

${ }^{41}$ No conozco ningún documento que especifique que don Juan de Santiago fuera señor de Atoyac; es mencionado como un señor de Tonalá. Sin embargo, en vista de la inclusión de Atoyac en el señorío de Tonalá y la falta de documentos tempranos de Atoyac, no es improbable que, en realidad, fuera señor de Atoyac. Los documentos sobre Atoyac más tempranos que he encontrado son: AGN, Tierras, vol. 2988, exp. 114 (1583), que habla de doña María de San Miguel, viuda de don Pedro de San Miguel I; Tierras, vol. 5, exp. 1 (1589), merced a la comunidad de Atoyaque, de un sitio de estancia para ganado menor en el sitio llamado Ychcatengo (el posterior Tacachi); Mercedes, vol. 15, f. 16 (1589), merced a don Pedro de San Miguel II, cacique de Atoyaque, de un sitio de estancia para ganado menor en el sitio llamado Teymamatlalystlauaca; Mercedes, col. 15, f. 19v (1589): merced a don Felipe de
Concluyo que el documento trata de un acuerdo - $\mathrm{O}$ de una propuesta para un acuerdo- entre los señoríos de Ihualtepec (de don Carlos de Terrazas) y Atoyac (de don Juan de Santiago) sobre la distribución, en el marco de la herencia de don Francisco Gómez, cacique de Tonalá, de las salinas de Santa María y San Ildefonso en la región del Cerro de las Tortillas.

Queda ahora la pregunta: ¿cómo llegó un documento de Ihualtepec-Atoyac a San Vicente el Palmar? La res-

Guzmán, cacique de Atoyaque, de un sitio de estancia para ganado menor en el sitio llamado Tilantongo. Estos mismos señores aparecen como caciques de Tonalá: Mercedes, vol. 9, f. 196v (1567), merced a don Pedro de San Miguel I, cacique de Tonalá, de un sitio de estancia para ganado menor; Mercedes, vol. 15, f. 21 y 48-48v (1589): merced para don Miguel de Guzmán II, cacique de Tonalá, de un sitio de estancia para ganado menor en el sitio llamado Ytzonteconatlauaco; Tierras, vol. 85, exp. 2 (1589), merced a don Miguel de Guzmán II de un sitio de estancia para ganado menor en el sitio llamado Suchiteupa; Mercedes, vol. 19, f. 183v y 264 y Tierras, vol. 2726, exp. 1 (1594), merced a don Miguel de Guzmán II de de un sitio de estancia para ganado menor en el sitio llamado Tianquiztepec 'el Viejo'. 
Francisco Gómez + María (de Huitzilopusco)

Tonalá

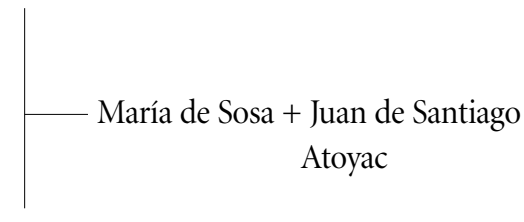

Carlos de Terrazas + Inés Gómez

Ihualtepec

Esquema 2. Esquema de las relaciones genealógicas de la familia gobernante de Tonalá.

puesta podría estar en la historia tardía del cacicazgo de Ihualtepec. En el siglo XVIII, la cacica doña Lucía de Terrazas de Ihualtepec obtuvo, gracias a una herencia que le había llegado a su esposo, las tierras del pueblo de San Vicente, 'de la jurisdicción de Tonalá', probablemente el actual San Vicente el Palmar"2 . A partir de este momento, las tierras de San Vicente formaron parte del cacicazgo de Ihualtepec. El Lienzo y algunas copias de documentos de doña Lucía de Terrazas, que ahora están en el pueblo, pueden haber llegado por este camino ${ }^{43}$.

La identificación del origen del Lienzo de San Vicente el Palmar tiene también consecuencias para otros documentos pictográficos del grupo comentado al inicio de este texto: el Mapa núm. 36 (fig. 16, p. 114) y su pariente, el Lienzo Mixteco III (fig. 18, p. 116) ${ }^{44}$. El primero, cuyo original pintado en papel europeo se encuentra en la Biblioteca Nacional de Antropología de México, mide 85 x $87 \mathrm{~cm}$. No se sabe cómo llegó al museo, aunque debió ser en alguna fecha anterior a 1907. El segundo, de aproxima-

42 Los documentos de San Vicente el Palmar hablan del cacicazgo de San Vicente y San Francisco.

${ }^{43}$ Tal esquema es muy parecido al de la historia del Códice Tulane, el cual fue pintado en Acatlán, aunque posteriormente, por acumulación de cacicazgos, llegó a parar en San Juan Ñumí (Smith y Parmenter, 1991). ${ }^{44} \mathrm{El}$ Lienzo es una copia decimonónica en papel transparente. La copia consiste de numerosas piezas de papel que deben ser armadas para apreciar el dibujo del lienzo; fue publicado por Joaquín Galarza (1986), quien ya señaló la similitud con el Mapa núm. 36. El documento se encuentra en la Biblioteca Pública y Universitaria de Ginebra, en la colección de Henri de Saussure. Véase Roguin y Weber, 1993, para las cartas de Saussure escritas en su viaje por México.

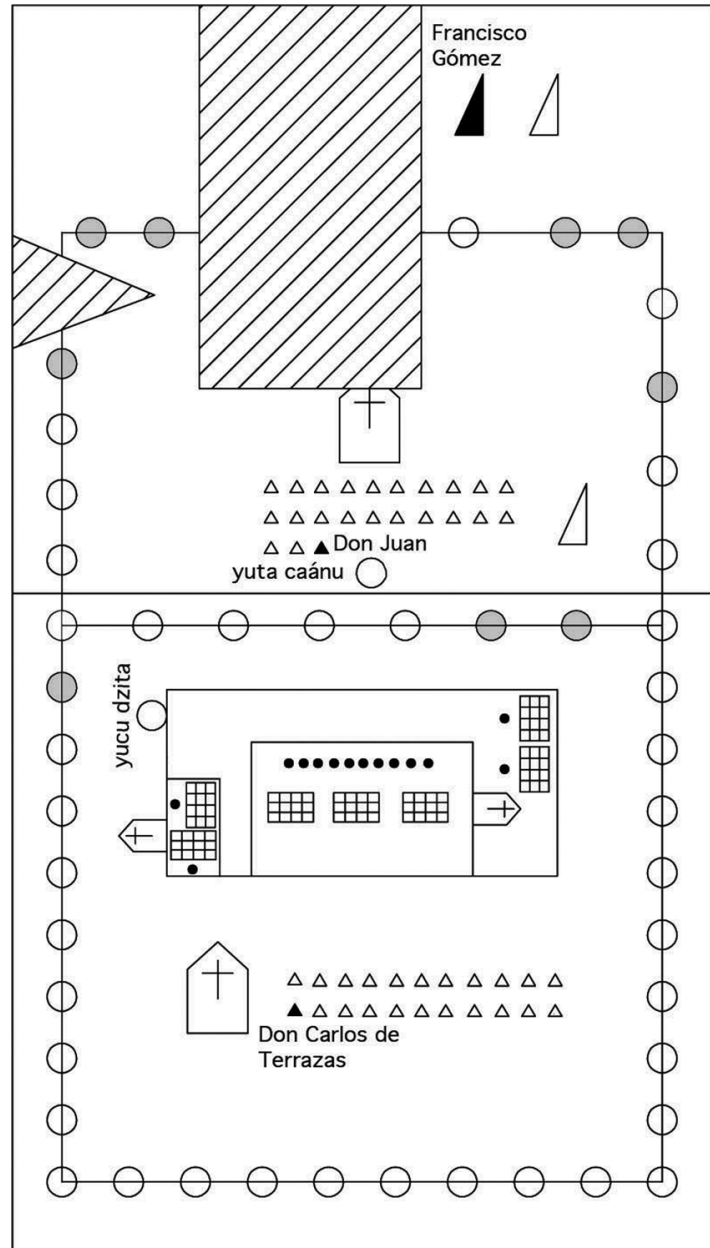

Esquema 3. Linderos en el Lienzo de San Vicente el Palmar que coinciden con linderos en el Mapa núm. 36.

damente 85 x $92 \mathrm{~cm}$, es copia de un documento hoy en día perdido, hecha por Henry de Saussure en su viaje por México durante los años de 1855 y 1856. Los dos documentos representan un señorío o una comunidad por medio de un rectángulo de topogramas en la orilla de la hoja y una iglesia en su centro, convención que ya comentamos al inicio de este texto. Las dos casas o palacios que aparecen al lado de la iglesia podrían representar dos parcialidades -o barrios étnicos - dentro del pueblo representado. En el Mapa núm. 36, cada casa tiene una fecha y una pareja de nobles — con nombres calendáricos en 


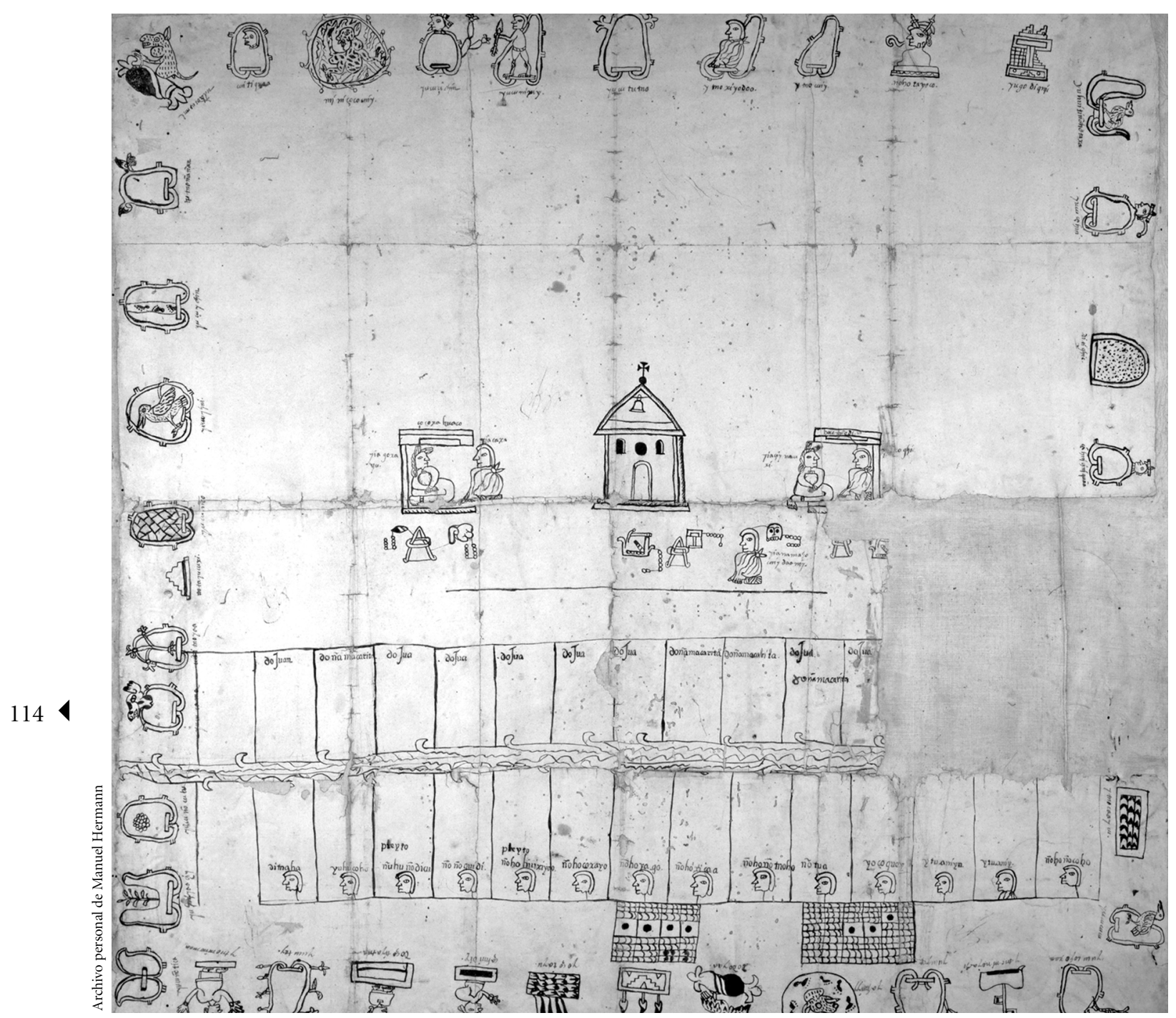

Figura 16. Mapa núm. 36.

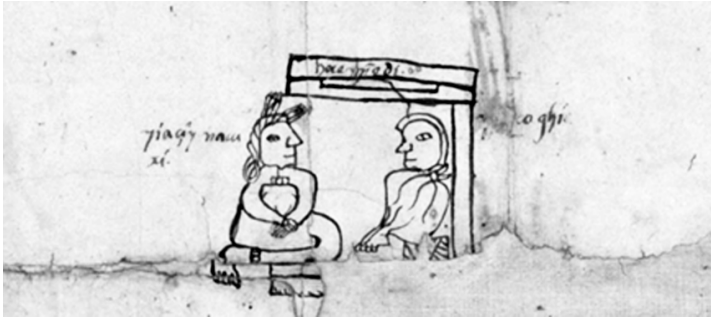

Figura 17. 'Casa de Nodi'. forma de glosas — sentada en su interior, indicando que se trata de una casa de linaje noble. Como notó Smith, las casas en el Mapa núm. 36 llevan glosas: en una casa aparece la glosa haey ñodi, 'casa de Ñodi', en la cual quizás se represente el nombre mixteco de Huajuapan - $\tilde{N} u u d-$ $z a i$, en la variante de Teposcolula-, sugiriendo que esta parcialidad fue una fundación de gente de Huajuapan (fig. 17). La existencia de parcialidades en los pueblos pre- 


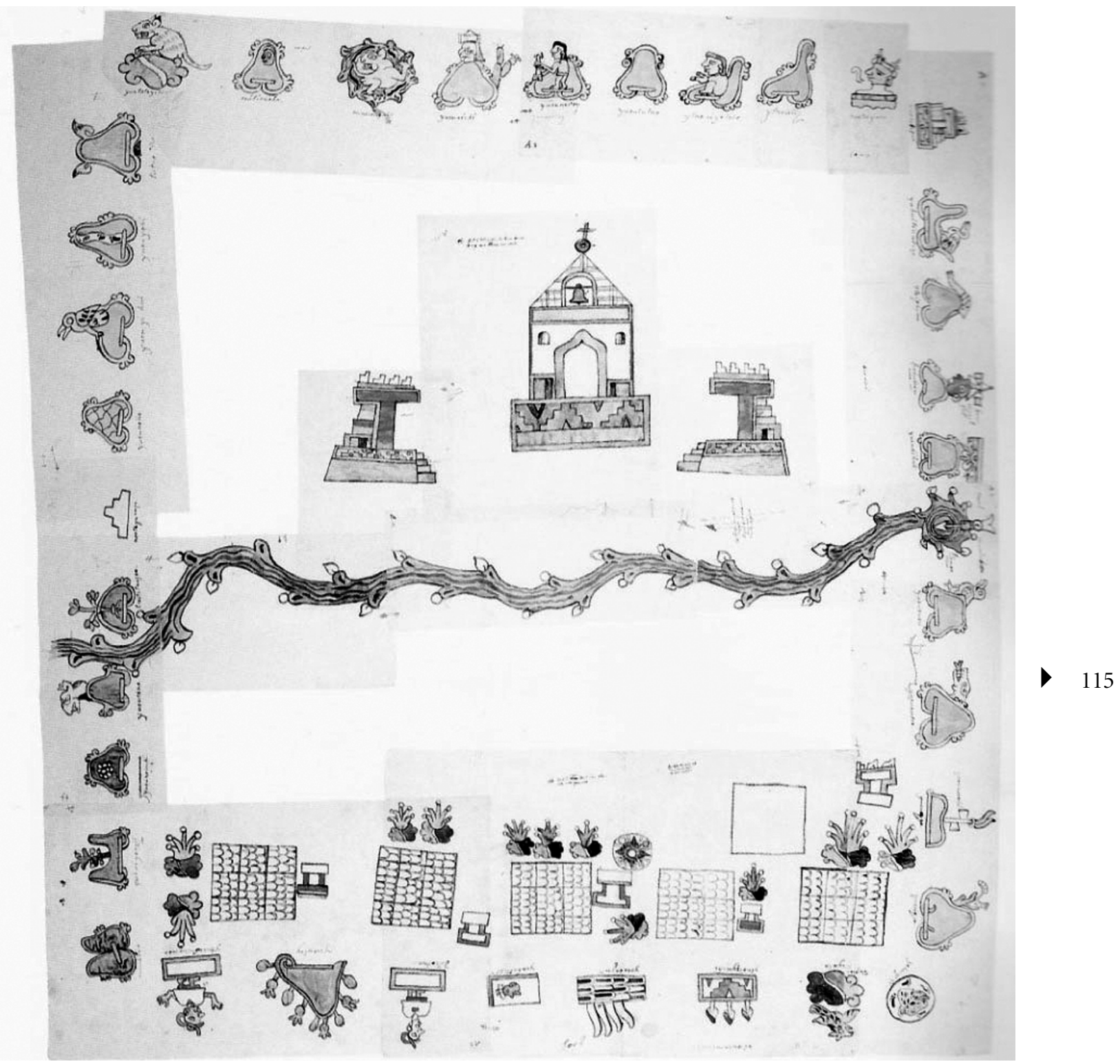

Figura 18. Lienzo Mixteco III.

hispánicos era una situación común, pero pocas veces reconocida por la administración española.

Smith (en Smith y Parmenter, 1991: 95), siguiendo la sugerencia de Galarza, demostró que el Mapa núm. 36 y el Lienzo Mixteco III dibujan los mismos linderos y, por lo tanto, representan al mismo pueblo. También notó que algunos de estos linderos coinciden con linderos en el Lienzo de San Vicente. De hecho, como podemos observar en el esquema 3 (p. 113), las coincidencias se reducen a la parte que, según sabemos ahora, representa al señorío de Atoyac. Los linderos que coinciden —no sólo en nombre, sino también en secuencia- son [las cursivas 


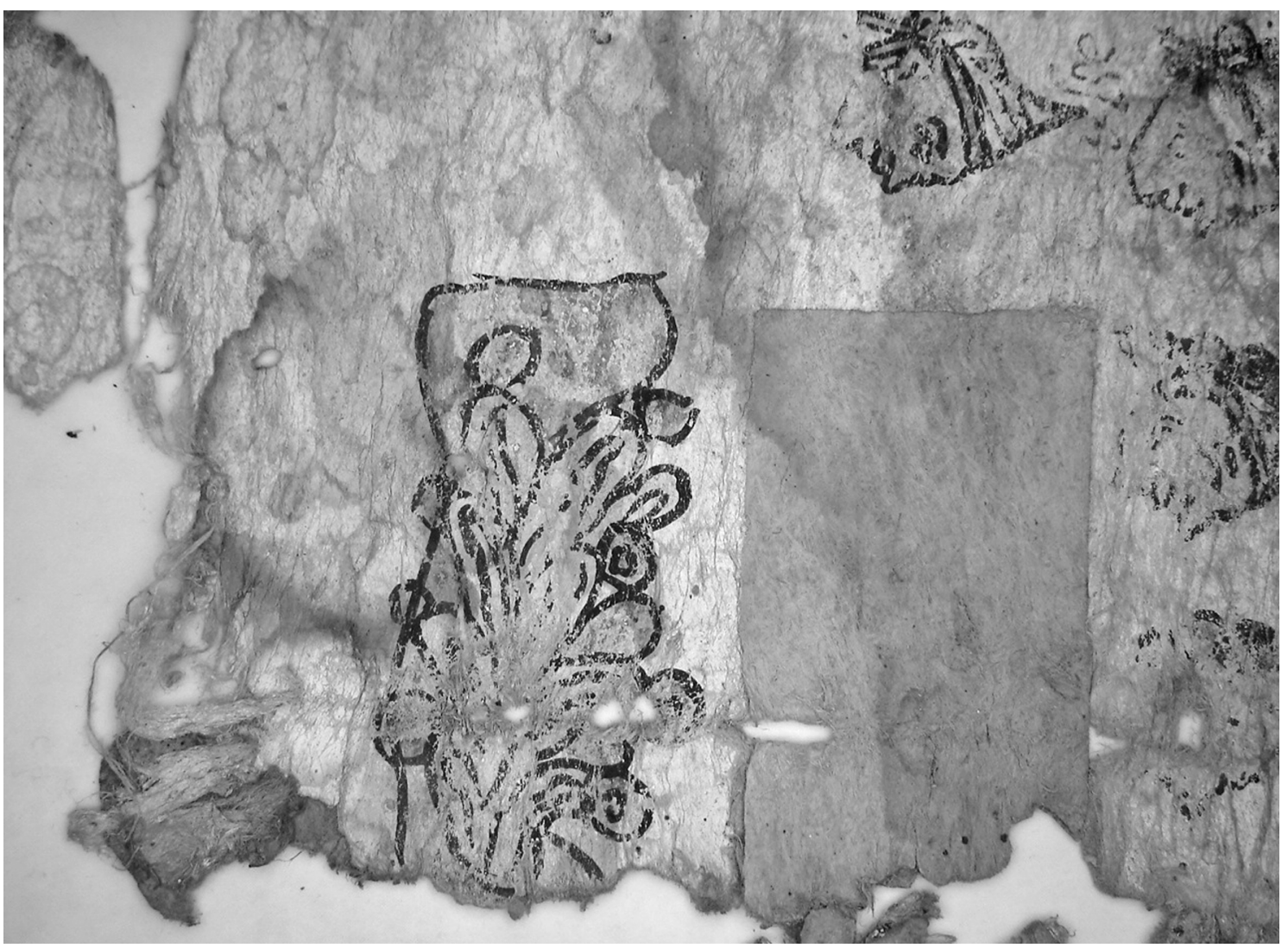

Figura 19. El topograma de Atoyac en el Lienzo de San Vicente el Palmar.

indican las partes legibles de las glosas en el Lienzo de San Vicente]:

Cerro del Camino ( yucu ychin),

Orejas del Gato (tutno ñaña),

Barranca del Faisán (yuhui tiñoho taxa),

Lugar Salpicado (ditiqhic),

Dzahui de Cabeza Roja (çahui çini quaá),

Cerro de la Palomita ( уиси сисu),

Cerro de Serpiente (yucu coho xaa),

Cerro Partido (yucu ñotica),

Barranca del Chile (yuhui yaa çiy),

Frente al Altar Blanco (no tayu cuixi).

Concluyo, entonces, que el Mapa núm. 36 y el Lienzo Mixteco III representan al señorío de Atoyac y no al de
Huajuapan, como pensó Smith. De nuevo vemos que la orientación de los documentos es con el oriente hacia arriba. En la parte inferior de los mapas se ve un río que atraviesa los documentos de derecha a izquierda. Su curso y dirección coinciden perfectamente con el río Mixteco, que pasa al poniente de Atoyac con una orientación surnorte (mapa 4, p. XX). De hecho, la ubicación del topograma de Atoyac en el Lienzo de San Vicente el Palmar coincide con la ubicación del río. Aparte de representar el nombre de San Pedro Atoyac, este topónimo también representa el nombre del río Mixteco (yuta cahnu - 'río grande'; atoyac - 'en el río') (fig. 19).

No obstante lo anterior, el Mapa núm. 36 y el Lienzo Mixteco III no representan el mismo asunto: en el Mapa núm. 36, en las orillas del río está representada una fila de terrenos divididos por el río mismo y perpendiculares a 


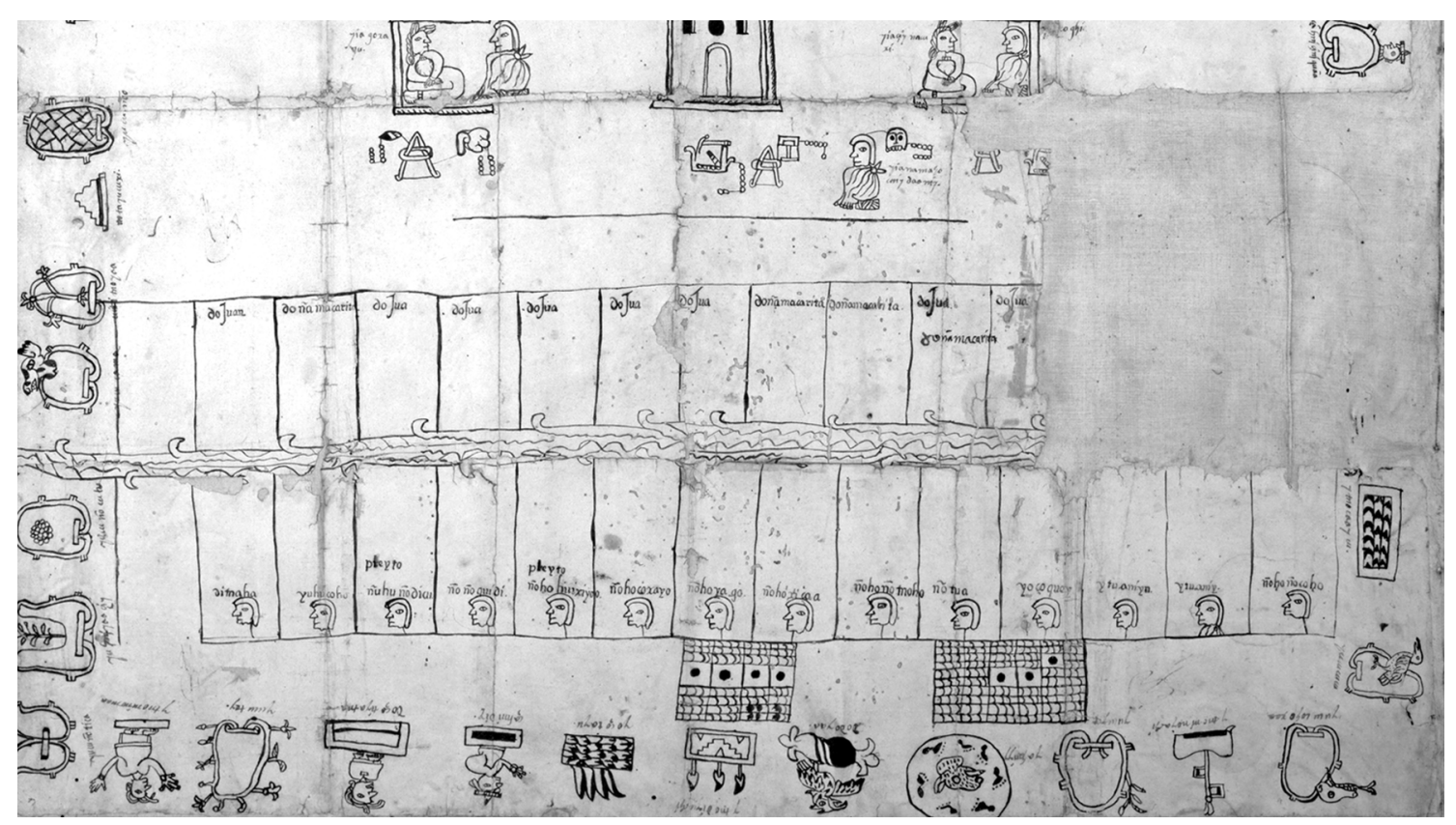

Figura 20. Fila de terrenos perpendiculares al río Mixteco en el Mapa núm. 36.

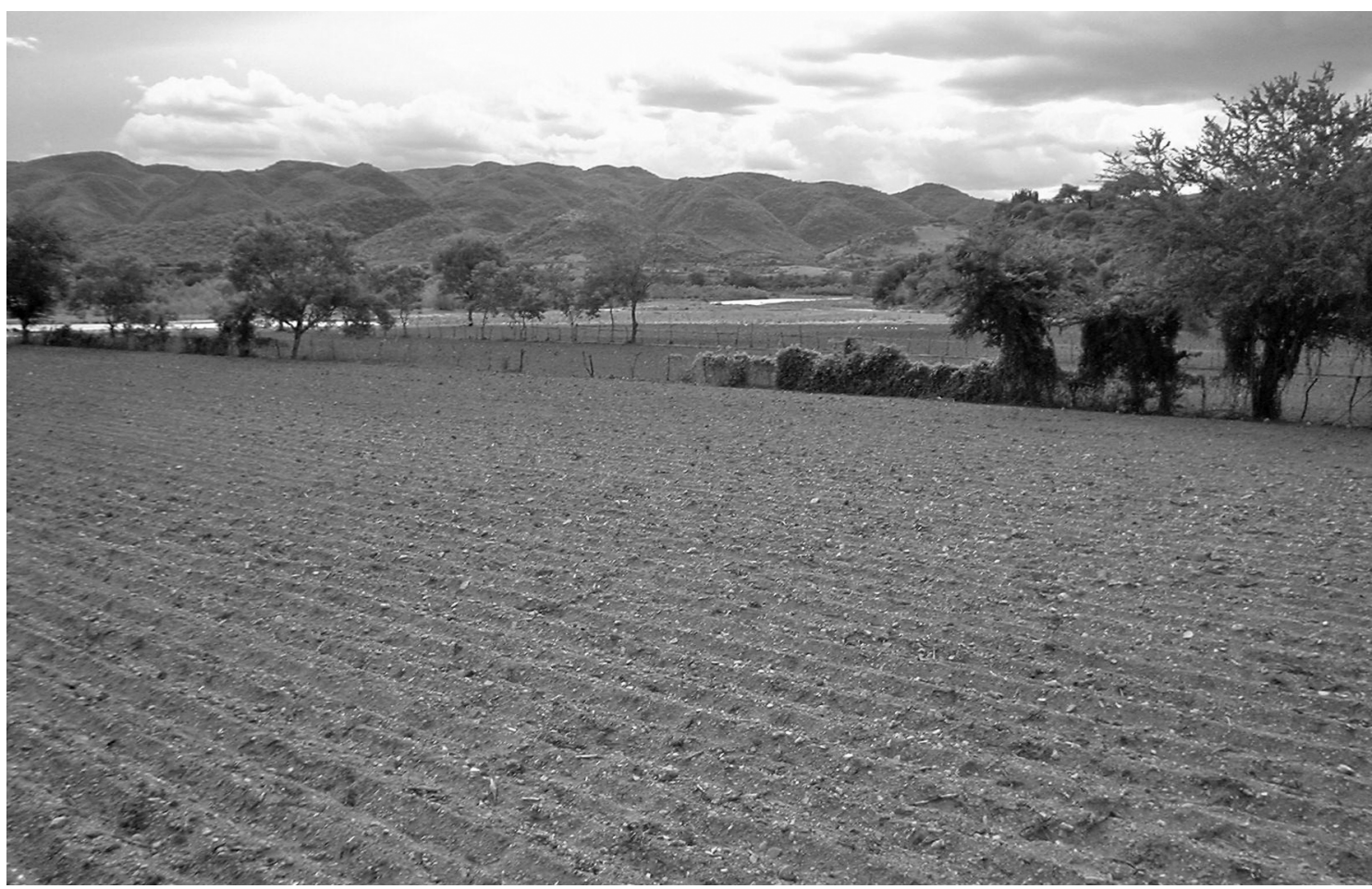

Figura 21. Terrenos de riego perpendiculares al río Mixteco en San Pedro Atoyac. 
él ${ }^{45}$. Estos terrenos estarían en lo que es el fértil llano de Atoyac, donde se abre la sierra de la Mixteca Baja en un extenso valle que permite la siembra de riego (figs. 20 y 21 , p. 117). Como ya observó Smith, la mayoría de los terrenos tienen inscrito el nombre de don Juan, pero otros llevan el nombre de doña Macarita, y uno tiene ambos nombres ${ }^{46}$. Este don Juan es probablemente el mismo que el don Juan representado en el Lienzo de San Vicente el Palmar y doña Margarita podría ser su hermana u otro pariente cercano ${ }^{47}$. Estos terrenos de riego representan probablemente tierras patrimoniales de la casa real de Atoyac. En dos terrenos aparece la palabra pleyto, lo que indica que el documento pudo ser compuesto durante un conflicto por estas tierras productivas. Smith (1973: 200) leyó en uno de los terrenos el nombre ñodiai, el cual interpretó como otra referencia al nombre de Huajuapan ( $\tilde{N} u u d z a i$ en la variante de Teposcolula). Sin embargo, el original dice ñodicu (ñuudzico en la variante de Teposcolula). Desafortunadamente no he podido encontrar documentación alfabética relacionada con este tema.

Al poniente de los terrenos aparecen dos dibujos que consisten en rectángulos subdivididos en pequeños cuadros, los cuales, a su vez, demuestran un motivo ondulado en su interior. Algunos cuadritos contienen puntos negros en lugar del motivo ondular. El significado de estos dibujos (que llamaré aquí "terrenos ondulados") es aún desconocido, pero no parece descabellado pensar que fuera una variante de las salinas.

En cuanto al Lienzo Mixteco III, el dibujo de este documento conserva mejor el estilo prehispánico de la escritura mixteca-puebla. Smith (en Smith y Parmenter, 1991: 95) sugirió que el Mapa núm. 36 podía ser una co-

\footnotetext{
45 Los terrenos representados al oriente del río llevan los nombres de los dueños, los occidentales los de los terrenos mismos. Por lo tanto, parece que los terrenos a ambos lados del río pertenecen unos a otros. 46 Las glosas que dan los nombres de los linderos y de los personajes en el Mapa núm. 36 parecen ser distintas (más 'cursivas') de las que dan los nombres de las tierras en el interior del documento.

47 Sin embargo, no fue posible identificarla en la documentación que he consultado. Desafortunadamente, tampoco queda clara la relación de don Juan con los gobernantes dibujados en el centro del documento. En el Lienzo de San Vicente, el antecesor de don Juan parece ya haber tenido un nombre católico (en la glosa muy destruida parece leerse donag [ustin]), pero los nombres de muchos de sus ancestros más antiguos resultan ilegibles.
}

pia del original de este documento, pero también puede pensarse en un prototipo perdido para las dos versiones. También observó que la temática del Lienzo Mixteco III parece ser distinta a la de su pariente: no aparecen los terrenos en el río tan obvios en el Mapa núm. 36. Por otro lado, vemos cinco terrenos casi idénticos a los dos "terrenos ondulados" del Mapa núm. 36, y también, como en el Mapa núm. 36, ubicados al poniente del río, acompañados en cada caso por una casa (quizás una población de trabajadores) y por manantiales representados como chorros de agua que salen de peñas. Por su ubicación (al poniente del río y más allá de los terrenos en la vega) se podría pensar de nuevo en una representación de salinas. En tal caso, los puntos negros en el Mapa núm. 36 podrían representar el número de manantiales o la producción de éstos. El Lienzo Mixteco III podría representar un punto de vista de Atoyac sobre la posesión de las salinas peleadas. Desafortunadamente, no ha sido posible identificar documentación relacionada con las dos pictografías, por lo que una identificación de la situación que llevó a su elaboración resta por descubrir.

Queda por comentar el tema de los linderos tan prominentes en los tres documentos bajo discusión. La hipótesis avanzada en esta contribución en cuanto a la procedencia de estos documentos debería convertirse en una pauta para la fácil identificación de los linderos de Ihualtepec y Atoyac. Sin embargo, no es así. No he podido identificar algún documento que proporcione los nombres antiguos en mixteco de los linderos de estas comunidades ${ }^{48}$. Hoy, los linderos de la antigua comunidad de

\footnotetext{
48 Tampoco he podido identificar en la documentación antigua alguna referencia a los documentos pictográficos, aunque en el transcurso de la investigación surgió una referencia a un códice: en 1743, un testigo en un pleito entre el pueblo de Atoyaque y el cacique Miguel de Alvarado y Guzmán (quien dijo ser cacique de Calihuala y Atoyaque) aseguró que el cacique tenía en su casa "el mapa que tendrá como dos varas de largo que está en pergamino doblado en cuatro dobleces en que están todos los parajes de este pueblo con grande individualidad pintados y señalados". El cacique dijo que no era para tanto y que "sólo consta en dicho mapa los linderos de su cacicazgo". No quería ir a su casa por el mapa, por estar lejos de ella, pero prometió presentarlo en la real audiencia en veinte días (AGN, Tierras, vol. 5, exp. 1 y 3 , f. 65 y 72v). Se trata claramente de un documento pictográfico y la descripción apunta a un fragmento de un códice antiguo anotado posteriormente con nombres de linderos: se habla de un pergamino con cuatro doble-
} 
San Pedro Atoyac han desaparecido por completo debido a los importantes cambios en la tenencia de la tierra en esta parte de la Mixteca Baja. El fértil llano en las orillas del río atrajo la atención de todo tipo de personas. A finales del siglo XIX, el antiguo territorio estaba dividido en por lo menos cinco partes. En el sur, la señora María de Luz Ramírez era dueña de más de una cuarta parte del territorio. En este terreno se encontraba el pueblo de Asuchixtlán - hoy Guadalupe Ramírez - y el rancho de Zocoteaca, conformados por trabajadores de la señora. Esta parte colindaba con las salinas de San Ildefonso. Los terrenos alrededor del pueblo de San Nicolás, al oeste del río Mixteco, pertenecieron a la Sociedad Agrícola de San Nicolás Hidalgo. Otra parte era propiedad de la hacienda La Pradera, fundada por don José Gómez en 1865 para el cultivo de la caña y cuyas ruinas aún están a la vista el día de hoy. Esta parte incluía al pueblo de Tacachi de Mina, fundado en la parte llamada antiguamente Ichcaatengo. Esta hacienda siguió una voraz política de apropiación de terrenos, por lo que llegó a reclamar incluso los terrenos sobre los que el pueblo de Atoyac estaba establecido como pago por unas cargas de cal con altos intereses. El pueblo mismo había sido refundado en 1735 aproximadamente a un poco más de un kilómetro al norte del 'pueblo viejo', cuyas ruinas aún existen ${ }^{49}$. En el norte, una pequeña extensión de terrenos perteneció a la Sociedad Agrícola de Mariscala. Ninguno de los linderos en torno a este territorio dividido - que Atoyac siguió reclamando como suyo- llevaba un nombre en mixteco, por lo que no parecen formar una lista muy antigua. No he localizado listas más antiguas, por lo que la identificación de los linderos de los lienzos en el paisaje actual queda como tarea pendiente.

ces, o sea, del material y de la forma de los antiguos códices. Dos varas equivalen a aproximadamente $166 \mathrm{~cm}$., pero como se trata de una descripción con base en la memoria del testigo de un documento visto unos quince años antes de la fecha en que dio su declaración, esta medida es sólo indicativa.

${ }^{49} \mathrm{AGN}$, Tierras, vol. 5, exp. 1, f. 63v.

\section{CONCLUSIONES}

Los distintos documentos comentados en este trabajo están relacionados con los señoríos de Ihualtepec, Tonalá y Atoyac en la parte occidental de la Mixteca Baja. Cubren un área que hasta hoy quedó en blanco en el mapa etnohistórico de Oaxaca, pero que conforma el punto de contacto entre la Mixteca Alta, la región de Tlapa (o Tlachinollan) en Guerrero y la región de Acatlán en Puebla ${ }^{50}$.

Cada uno de estos documentos trata un tema puntual, coyuntural y relacionado con los intereses bien precisos del momento de su manufactura. Sin embargo, juntos, y como un corpus interrelacionado, conforman una buena muestra de la temática existente en la documentación de los señoríos indígenas en esta región. El primer documento, el Lienzo de San Vicente, se vincula con el control de la producción de los recursos naturales especiales, como era la sal, que definía el poder de los gobernantes de los señoríos. El documento parece representar algún acuerdo -o propuesta para un acuerdo- entre dos señoríos $\mathrm{y}$ bien puede haber sido un documento de uso interno. El segundo documento, el Mapa núm. 36, está relacionado con la posesión y la administración de las tierras de alta producción (o sea, de riego), que representaban la base agrícola con que se sostenían los señoríos indígenas. Parece ser un mapa que, en su origen, acompañó un expediente judicial referente a un pleito por tierras de riego, hecho exclusivamente para tal fin. La temática del tercer documento, el Lienzo Mixteco III, aún no queda definida, aunque la presencia de las salinas sugiere algún asunto relacionado con éstas. La 'lectura' o, mejor dicho, la interpretación del mensaje de estos documentos se obtiene por medio de la contextualización y la comparación de los documentos, relacionándolos con la documentación alfabética existente en los archivos y con el paisaje y la geografía real. Haber identificado el origen de estos documentos ofrece ahora la posibilidad de vincularlos con personas y lugares reales y enriquecer así la historia de esta región olvidada de Oaxaca.

\footnotetext{
${ }^{50}$ Este 'mapa en blanco' lo encontramos en Caso (1977-1979) y, posteriormente, en Vega (1991: 34) y Hermann (2006: 9).
} 


\section{Siglas y bibliografía}

AGEO: Archivo General del Estado de Oaxaca

AGN: Archivo General de la Nación

Acuña, René (ed.), 1984, Relaciones geográficas del siglo XVI: Antequera, t. I, Universidad Nacional Autónoma de México, México.

Anales de Cuauhtitlán, 1975, Universidad Nacional Autónoma de México, México.

Boone, Elizabeth Hill, 2000, Stories in Red and Black. Pictorial Histories of the Aztecs and Mixtecs, University of Texas Press, Austin.

— y Walter Mignolo (eds.), 1994, Writing without Words: Alternative Literacies in Mesoamerica and the Andes, Duke University Press, Durham.

Byland, Bruce, 1980, Political and Economic Evolution in the Tamazulapan Valley, Mixteca Alta, Oaxaca, México: A Regional Approach, tesis de doctorado, Departamento de Antropología, Universidad Estatal de Pensilvania.

Caso, Alfonso, 1949, "El Mapa de Teozacualco", Cuadernos Americanos, vol. VIII, núm. 5, Cultura, México, pp. 145 181.

__, "El Mapa de Xochitepec", 1958, Proceedings of the 32 ${ }^{\text {nd }}$ International Congress of Americanists (Copenhagen, 1956), Munksgaard, Copenhague.

_ 1977-1779, Reyes y reinos de la Mixteca, 2 vols., Fondo de Cultura Económica, México.

Dahlgren de Jordan, Barbro, 1954, La Mixteca, su cultura e historia prehispánicas, Universidad Nacional Autónoma de México, México (col. Cultural Mexicana, núm. 11).

DeFrancis, John, 1989, Visible Speech: The Diverse Oneness of Writing Systems, University of Hawaii Press, Honolulu.

Doesburg, Sebastián van, 2000, "Origin of the Lienzo de Tulancingo. New Facts about a Pictographic Document from the Coixtlahuaca Region", Ancient Mesoamerica, núm. 11, pp. 169-183.

— 2001a, Códices cuicatecos Porfirio Díaz y Fernández Leal, Miguel Ángel Porrúa, México.

_ 2001b, "The Codex Porfirio Díaz and the Map of Tutepetongo: The Curious Relationship between Pictography and Glosses in Oaxacan Screenfolds", Ethnohistory, vol. 48, núm. 3, pp. 403-432.

_ 2003 , "El siglo XVI en los Lienzos de Coixtlahuaca", Journal de la Société des Américanistes, vol. 89, núm. 2, pp. 67-96.

Ewald, Ursula, 1985, The Mexican Salt Industry. 1560-1980. A Study in Change, Gustav Fischer Verlag, Stuttgart, Nueva York.
Fernández de Recas, Guillermo, 1961, Cacicazgos y nobiliario de la Nueva España, Universidad Nacional Autónoma de México, México.

Flannery, Kent y Joyce Marcus (eds.), 1983, The Cloud People. Divergent Evolution of the Zapotec and Mixtec Civilizations, Academic Press, Nueva York, Londres.

Furst, Jill Leslie, 1978, Codex Vindobonensis Mexicanus I: A Commentary, Institute for Mesoamerican Studies, State University of New York, Albany.

Galarza, Joaquín, 1979, Estudios de escritura indigena tradicional azteca náhuatl, Archivo General de la Nación, México.

_, 1986, "Découverte de codex mexicains à Genève. La Collection Henri de Saussure de 1855", Bulletin de la Société Suisse des Américanistes, núm. 50, pp. 7-41.

Gaxiola, Margarita, 1976, Excavaciones en San Martín Huamelulpan, Oaxaca, 1974, tesis de maestría, Escuela Nacional de Antropología e Historia, México.

Gerhard, Peter, 1986, Geográfica Histórica de la Nueva España, 1519-1821, Universidad Nacional Autónoma de México, México.

Handbook of Middle American Indians, 1975, vol. 14, University of Texas Press, Austin.

Hermann Lejarazu, Manuel, 1998, “Códice Mixteco PostCortesiano núm. 36”, en Códices mexicanos. Lienzo de Zacatepec, Códice Mixteco Post-Cortesiano no. 36, Códice Colombino [libro que acompaña el video de este códice], Instituto Nacional de Antropología e Historia, Instituto de Cultura Oaxaqueña, Fomento Cultural Banamex, A. C., Fideicomiso Amigos de Oaxaca, México.

—_, 2006, "Códice Nuttall”, Arqueología Mexicana, núm. 23, edición especial, México.

Herrera, María del Carmen y Ethelia Ruiz, 2000, "El Códice de Tepeucila, una prueba de escritura”, en Vega Sosa (ed.), Códices y documentos sobre México. Tercer Simposio Internacional, Instituto Nacional de Antropología e Historia, México.

Jansen, Maarten, 1979, "Apoala y su importancia para la interpretación de los códices Vindobonensis y Nuttall”, Actes du XLIIe Congrès International des Américanistes (París, 1976), vol. 7, París, pp. 161-171.

- 1988, "The Art of Writing in Ancient Mexico: An Ethno-iconological Perspective”, Visible Religion, núm. 6, Brill, Leiden, pp. 86-113.

_ 2000 , "Los fundamentos para una 'lectura lírica' de los códices", en La dinastía de Añute. Historia, literatura e ideología de un reino mixteco, Universidad de Leiden, Leiden (CNWS Publications, 87), pp. 214-226. y Aurora Pérez Jiménez, 2005, Codex Bodley. A Painted Chronicle from the Mixtec Highlands, Mexico, Bodleian Library, University of Oxford, Oxford. 
König, Viola, 1979, Inhaltliche Analyse und Interpretation von Codex Egerton, Hamburgischen Museum für Völkerkunde, Hamburgo (Beiträge zur Mittelamerikanischen Völkerkunde, XV).

Libro de Tasaciones, 1952, Archivo General de la Nación, México.

Lind, Michael, 1979, Postclassic and Early Colonial Mixtec Houses in the Nochixtlán Valley, Oaxaca, Vanderbilt University, Nashville, Tennessee (Vanderbilt University Publications in Anthropology, 23).

Loo, Peter van der, 1987, Códices, costumbres, continuidad. Un estudio de la religión mesoamericana, Centro Arqueológico, Universidad de Leiden, Leiden (Indiaanse Studies, 2).

Moser, Christopher, 1972, "Nuiñe Hieroglyphics of the Mixteca Baja”, en Religión en Mesoamérica. Memorias de la XII Mesa Redonda de la Sociedad Mexicana de Antropología, Sociedad Mexicana de Antropología, México, pp. 269-274.

__ 1977, Nuiñe Writing and Iconography of the Mixteca Baja, Vanderbilt University, Nashville, Tennessee (Vanderbilt University Publications in Anthropology, núm. 19).

Nicholson, H. B, 1960, "The Mixteca-Puebla Concept in Mesoamerican Archeology: A Re-examination”, en Men and Cultures: Selected Papers from the Fifth International Congress of Anthropological and Ethnological Sciences, Philadelphia, University of Pennsylvania, Pennsylvania, pp. 612-617.

— y Eloise Quiñones Keber (eds.), 1984, Mixteca-Puebla. Discoveries and Research in Mesoamerican Art and Archaeology, Labyrinthos, Culver City, California.

Paddock, John, 1953, "Excavations in the Mixteca Alta", Mesoamerican Notes, núm. 3, University of the Americas.

_, 1965 , "Current Research: Western Mesoamerica”, American Antiquity, vol. 31, núm. 1, pp. 133-136.

_ 1966 , "Oaxaca in Ancient Mesoamerica", en Paddock (ed.), Ancient Oaxaca: Discoveries in Mexican Archaeology and History, Stanford University Press, Stanford, pp. 83-242.

__ 1968, "Una tumba en Nuyoo, Huajuapan de León, Oaxaca”, Boletín del Instituto Nacional de Antropología e Historia, época I, núm. 33, pp. 51-54.

_ $1970 a$ a, "A Beginning in the Nuiñe: Salvage Excavations at Nuyoo, Huajuapan", Boletín de Estudios Oaxaqueños, núm. 26, Museo Frissel de Arte Zapoteco, Mitla.

_, 1970 b, "More Nuiñe Materials", Boletín de Estudios Oaxaqueños, núm. 28, Museo Frissel de Arte Zapoteco, Mitla.

Parmenter, Ross, 1966, "Break-Through on the Lienzo de Filadelfia”, Expedition, vol. 8, núm. 2, pp. 14-22.
-, 1997, “A Nativitas Ruler List on Lienzo A”, en Códices $y$ documentos sobre México. Segundo Simposio, vol. 1, Instituto Nacional de Antropología e Historia, México, pp. 269-303.

Pohl, John, 1984, The Earth Lords: Politics and Symbolism of the Mixtec Codices, tesis de doctorado, Departamento de Antropología, Universidad de California, Los Ángeles.

Rabin, Emily, 1974, Some Problems of Chronology in Mixtec Historical Manuscripts, ponencia presentada en el $41^{\circ}$ Congreso de Americanistas, México.

_, 2003 , "Toward a Unified Chronology of the Historical Codices and Pictorial Manuscripts of the Mixteca Alta, Costa and Baja: An Overview", Patricia Plunket (ed.) Homenaje a John Paddock, Universidad de las Américas, Cholula, pp. 101-138.

Reyes, fray Antonio de los, Arte en lengua mixteca, 1976 [1593], Vanderbilt University, Nashville, Tennessee (Vanderbilt University Publications in Anthropology, 14).

Rivera Guzmán, Ángel Iván, 1999, El patrón de asentamiento en la Mixteca Baja de Oaxaca: análisis del área de Tequixtepec-Chazumba, tesis de maestría, Escuela Nacional de Antropología e Historia, México.

Rodríguez Cano, Laura, 1995, El sistema de escritura ñuiñe en la Mixteca Baja de Oaxaca, México, en el sitio <http: //www.famsi.org/reports/94013es>.

Roguin, Louis de y Claude Weber, 1993, Henri de Saussure. Voyage aux Antilles et au Mexique, 1854-1856, Olizane, Ginebra.

Romero Frizzi, María de los Ángeles, 1975, Los conflictos por la tierra en San Martín Huamelulpan, Mixteca Alta, Oa$x a c a$, Centro Regional de Oaxaca, Instituto Nacional de Antropología e Historia, Oaxaca.

__, 1990, Economía y vida de los españoles en la Mixteca Alta: 1519-1720, Instituto Nacional de Antropología e Historia, Gobierno del Estado de Oaxaca, México.

Sampson, Geoffrey, 1985, Writing Systems: A Linguistic Introduction, Stanford University Press, Stanford.

Smith, Mary Elizabeth, 1963, “The Codex Colombino: A Document of the South Coast of Oaxaca”, Tlalocan, vol. 4, núm. 3, México, pp. 276-288.

_- 1973, Picture Writing from Ancient Southern Mexico: Mixtec Place Signs and Maps, University of Oklahoma Press, Norman.

— 1979, “Codex Becker II: A Manuscript from the Mixteca Baja?”, Archiv für Völkerkunde, núm. 33, pp. 29-43.

_ 1998, The Codex López Ruiz. A Lost Mixtec Pictorial Manuscript, Vanderbilt University, Nashville, Tennessee (Vanderbilt University Publications in Anthropology, 51). 
_ y Ross Parmenter, 1991, The Codex Tulane, Akademische Druck $u$ Verlagsanstalt, Graz y Middle American Research Institute, Tulane University, Tulane.

Spores, Ronald, 1967, The Mixtec Kings and Their People, University of Oklahoma Press, Norman.

- 1984, The Mixtecs in Ancient and Colonial Times, University of Oklahoma Press, Norman.

Troike, Nancy, 1974, The Codex Colombino-Becker, tesis de doctorado, Departamento de Antropología, Universidad de Londres.

Urcid, Javier, 2004, Paisajes sagrados y memoria social: las inscripciones ñuiñe en el Puente Colosal, Tepelmeme, Oaxa$c a$, en el sitio <http://www.famsi.org/reports/03068 es>.

Vega Sosa, Constanza, 1991, Códice Azoyu 1. El Reino de Tlachinollan, Fondo de Cultura Económica, México.
Viramontes, Carlos, 1993, "La producción tradicional de sal en un sitio de la Mixteca Baja, Oaxaca. Un estudio comparativo“, Cuadernos del Sur, núm. 4, pp. 5-25.

Winter, Marcus, 1989, "Exploraciones en Cerro de las Minas, 1987”, Notas Mesoamericanas, núm. 11, Universidad de las Américas, Puebla, pp. 304-317.

, 1996, Cerro de las Minas. Arqueología de la Mixteca Baja, Casa de la Cultura de Huajuapan de León, Oaxaca. , Daria Deraga y Rodolfo Fernández, 1976, “Cerro de la Codorniz: una zona arqueológica ñuiñe en Santiago Chilixtlahuaca, Huajuapan, Oaxaca", Boletín del Instituto Nacional de Antropología e Historia, época II, núm. 17, pp. 29-40. 